\title{
De monstruos y fenómenos naturales. Historia cíclica, presagios y destrucción de imperios en el Altiplano Central durante el Posclásico
}

\author{
Of Monsters and Natural Phenomena. Cyclical History, Omens and \\ Destruction of Empires in the Central High Plateau in the Postclassic Period \\ Jaime Echeverría García \\ ESCUELA NACIONAL DE ANTROPOLOGÍA E HISTORIA, jecheverriagarcia@yahoo.com
}

En el pensamiento nahua precolombino, el ocaso de ciudades e imperios era augurado por señas celestes y terrestres que rebasaban los eventos naturales y cotidianos de la vida diaria, y que por su misma extrañeza generaban un profundo terror. Estos vaticinios eran promovidos por las divinidades como consecuencia de las transgresiones que había cometido el gobernante. Las señales terrestres, encarnadas en la figura de monstruos, también anunciaban la imposición de un nuevo orden político. La destrucción y el advenimiento de imperios en el Altiplano Central durante el Posclásico forman parte de un mismo modelo de acontecimientos que pueden ser interpretados de manera semejante, lo que refuerza la concepción cíclica de la historia entre los antiguos nahuas. Uno de los principales aportes del texto es el abordaje del monstruo desde una visión mesoamericana, donde se destaca el simbolismo de sus características físicas particulares y su significado en la cosmovisión nahua.

PALABRAS ClAVE: nahuas, presagios, monstruo, caída de imperios, historia cíclica.

In the pre-Hispanic Nahua way of thinking, the decline of cities and empires was predicted by both celestial and terrestrial signs that exceeded natural, ordinary events of everyday life and that, due to their very strangeness, caused deep terror among the people. These omens were believed to be engendered by divinities as a consequence of transgressions committed by rulers. But these terrestrial signs in the form of awful apparitions of monsters also announced the imposition of a new political order. The destruction of old empires and the emergence of new ones in Mexico's Central High Plateau in the Postclassic period followed this model of events, and can be interpreted in a similar way, reinforcing a cyclical conception of history among the ancient Nahuas. One of the main contributions of this paper is its analysis of monsters from a Mesoamerican point of view that highlights the symbolism of their particular physical characteristics and their meaning in the Nahua worldview.

KeYwORDS: nahuas, omens, monsters, fall of empires, cyclical history.

Fecha de recepción: 20 de enero de 2015 / Fecha de aceptación: 10 de agosto de 2015 / Fecha de versión definitiva: 7 de febrero de 2017 
A partir del estudio de los mitos nahuas prehispánicos, Michel Graulich ${ }^{1}$ ha visto un proceso cíclico de sucesión entre orden y desorden en la historia de una era, un pueblo, una vida y un año, que sigue el modelo del día de la alternancia entre la luz y la oscuridad. Dicho proceso se puede resumir en tres puntos: 1) unión de los contrarios; 2) separación de los contrarios; 3) equilibrio de los contrarios basado en su alternancia. El detonante de la destrucción de una era y el paso a otra es la transgresión que cometieron los habitantes de aquélla, la cual recuerda la falta original perpetrada en Tamoanchan por los dioses. ${ }^{2}$ En este esquema, el desorden no se ve como algo negativo, sino como un aspecto que le da dinamismo al cosmos.

Las destrucciones de imperios y el advenimiento de nuevos también se encuentran enmarcadas dentro del mismo modelo delineado por el investigador belga. Un orden político imperante era equiparado con una era o Sol, y su caída, la destrucción de dicha era; mientras que la instauración o imposición de un nuevo imperio se interpretaba como una nueva edad. En concordancia, el gobernante era equiparado con el astro diurno. ${ }^{3}$ En un momento de la historia del imperio, el tlatoani incurría en transgresiones, como

${ }^{1}$ Michel Graulich, Mitos y rituales del México antiguo, trad. Ángel Barral Gómez (Madrid: Colegio Universitario de Ediciones Istmo, 1990), 16, 288.

${ }^{2}$ Códice Telleriano-Remensis, en Antigüedades de México, basadas en la recopilación de Lord Kingsborough, tomo I, ed., José Corona Núñez, lám. 19r, 223 (México: Secretaría de Hacienda y Crédito Público, 1964); a partir de aquí CTR. Códice Vaticano Latino 3738, en Antigüedades de México, basadas en la recopilación de Lord Kingsborough, tomo III, ed. José Corona Núńez, lám. 27v, 103 (México: Secretaría de Hacienda y Crédito Público, 1964); a partir de aquí, CVL 3738; Graulich, Mitos y rituales, 72.

${ }^{3}$ Fray Bernardino de Sahagún, Los once discursos sobre la realeza. Libro sexto del Códice Florentino, ed. Salvador Díaz Cíntora (México: Universidad Nacional Autónoma de México, 1995), lib. vi, cap. Iv, fol. 12v, p. 19, cap. v, fols. 16v, p. 31, 18r, p. 32; Fray Diego Durán, Historia de las Indias de Nueva España e islas de tierra firme, tomo I, tratado I, cap. XLI, ed. Rosa Camelo y José Rubén Romero, 375 (México: Consejo Nacional para la Cultura y las Artes, Cien de México, 2002); Leyenda de los Soles, en Mitos e historias de los antiguos nahuas, trad. Rafael Tena Martínez (México: Consejo Nacional para la Cultura y las Artes, Cien de México, 2002), 195-197; Guilhem Olivier, "Les paquets sacrés ou la mémoire cachée des Indiens du Mexique central (XVe-XVIe siècles)", Journal de la Société des Américanistes 81(1) (1995): 131; "Las tres muertes simbólicas del nuevo rey mexica: reflexiones en torno a los ritos de entronización en el México Central prehispánico", en Símbolos de poder en Mesoamérica, coord. Guilhem Olivier, 279 (México: Universidad 
también lo hacía su pueblo. ${ }^{4}$ Esto provocaba la cólera de las divinidades quienes enviaban a la Tierra diferentes señas que auguraban su ruina, y que además podían propiciarla.

Este proceso es muy similar al de la destrucción mítica de los Soles, en el que los fenómenos naturales en su máxima expresión se aprecian como la causa última de la hecatombe, en tanto que la causa profunda corresponde a la voluntad divina, que es motivada por la acción humana. Los nahuas pensaban que los dioses creaban los Soles, y que ellos mismos los hacían destruir. Pero si los dioses encolerizados provocaban las destrucciones, es porque previamente los hombres habían cometido graves faltas. Los ancestros les habían narrado que el mundo había sido destruido por las aguas, y, así, "todos los hombres fueron ahogados por causa de los pecados que habían cometido contra los dioses". ${ }^{5}$ También se dice que la destrucción de la cuarta edad, la cual les correspondió a los toltecas según los mexicas, se perdió por causa de sus vicios. Hubo grandes hambres, llovió sangre "y muchos murieron de espanto". ${ }^{6}$

Los eventos y las catástrofes naturales que ocasionaron la pérdida de las edades pasadas dejaron una impronta en la memoria colectiva de los pueblos nahuas, y determinaron en buena medida las posibles causas de destrucción de las ciudades. Así, el tlatoani de Cuauhtitlan, Coxcoxteuctli, al ser avisado de la destrucción de su ciudad por su nieto, se interrogó sobre las posibles causas de la misma y supuso que ocurriría por eclipses, temblores, enfermedades o guerras. ${ }^{7}$

En este trabajo estudio el papel que desempeñaron ciertos fenómenos naturales como eclipses, cometas y terremotos, y las apariciones monstruosas, como signos anunciadores de la destrucción

Nacional Autónoma de México, Instituto de Investigaciones Antropológicas, Instituto de Investigaciones Históricas, 2008).

${ }^{4}$ Michel Graulich, Mitos y rituales, 105.

5 "Histoyre du Mechique", en Mitos e historias de los antiguos nahuas, trad. Rafael Tena, cap. vi, 147 (México: Consejo Nacional para la Cultura y las Artes, Cien de México, 2002).

${ }^{6}$ CVL 3738, lám. 7r, 26.

${ }^{7}$ Anales de Cuauhtitlan, en Códice Chimalpopoca. Anales de Cuauhtitlan y Leyenda de los Soles, ed. Primo Feliciano Velázquez, 28 (México: Universidad Nacional Autónoma de México, Instituto de Historia, Imprenta Universitaria, 1945). 
venidera de un imperio, que además se vieron acompañados por otros acontecimientos como sequías, hambrunas, guerras y muerte de gobernantes. Ambos -fenómenos naturales y monstruos- fueron concebidos dentro de la categoría de tetzahuitl, que refiere a todos los eventos, apariciones, animales, cosas, e incluso determinadas personas, que rebasaban los límites de lo natural y lo cotidiano. Este carácter extraño del tetzahuitl provocaba espanto y pronosticaba hechos aciagos. Afirma Miguel Pastrana ${ }^{8}$ que la presencia del augurio "se registra con mayor intensidad y significación en circunstancias de crisis y cambio político y social". Y de mismo parecer es Guilhem Olivier," para quien "tanto los presagios como las prácticas adivinatorias surgen de manera más recurrente en situación de crisis o en contextos bélicos".

Los ejemplos que voy a tratar se centran en los últimos años de los imperios tolteca, tepaneca y mexica, en los cuales se manifestaron variados tetzahuitl que vaticinaron su caída. Los augurios en los que centro mi atención son los fenómenos naturales considerados como tales, y las visiones terrestres, es decir, la aparición de figuras monstruosas. Aunque ciertos tetzahuitl como el eclipse solar, el cometa y el terremoto, mantuvieron significados funestos específicos en la cosmovisión nahua, su conjunción auguraba un evento aún más dramático: la pérdida de la potencia política en turno y el cambio de poder. El abordaje de los augurios en tres momentos temporales distintos permite dar cuenta de la utilización de un modelo mítico-histórico nahua en la construcción de los hechos que vaticinaron la caída de imperios. ${ }^{10}$

Si bien los augurios de la caída de Tula y de Tenochtitlan nos son bien conocidos y han sido estudiados, siguiendo generalmente la vía de comparación entre ellos, ${ }^{11}$ la información concerniente al impe-

${ }^{8}$ Historias de la Conquista. Aspectos de la historiografía de tradición nábuatl, Serie Teoría e Historia de la Historiografía 2 (México: Universidad Nacional Autónoma de México, Instituto de Investigaciones Históricas, 2009), 25-26.

${ }^{9}$ Guilhem Olivier, "Indios y españoles frente a prácticas adivinatorias y presagios durante la conquista de México”, Estudios de Cultura Nábuatl (37) (2006): 170.

${ }^{10}$ Véase Guilhem Olivier, Tezcatlipoca. Burlas y metamorfosis de un dios azteca, trad. Tatiana Sule (México: Fondo de Cultura Económica, 2004), 248.

${ }^{11}$ Véanse Rocío Cortés, "Motecuzoma/Huemac y Quetzalcoatl/Cortés: referencia 
rio tepaneca y su caída es escasa. ${ }^{12}$ No obstante, ciertos datos alusivos a los últimos días de la hegemonía tepaneca en el Valle de México nos permiten enmarcar su derrumbe dentro del modelo anteriormente delineado, y así lo trataremos de demostrar.

\section{LA CONCEPCIÓN DE LA HISTORIA, EL PRESAGIO Y LA CONSTRUCCIÓN DEL EVENTO}

Al comenzar a hablar de los augurios de la destrucción de Tenochtitlan, fray Toribio de Benavente o Motolinía ${ }^{13}$ asentó lo siguiente:

La espiriençia nos enseńa y la Escritura Sagrada lo aprueua que quando alguna gran tribulación a de venir, o Dios quiere demostrar alguna cosa notable, primero muestra Dios algunas seńales en el cielo o en la tierra, demostratiuas de la tribulación venidera [...] Y daquí es que comúndmente, antes de las mortandades y pestilençias suelen aparesçer cometas, e antes de las grandes hambres anteçeden terremotos o tempestades, e antes de las destruyçiones de los rreynos y provinçias, aparesçen terribles visiones.

Las anteriores "señales prenósticos" que anteceden a la destrucción de ciudades son expresadas por Motolinía como afirmaciones uni-

mítica sobre el fin del imperio mexica en la Crónica mexicana de don Hernando de Alvarado Tezozomoc", Hofstra Hispanic Review (3) (otoño 2006); Michel Graulich, "Los presagios de la caída del imperio azteca", Cuicuilco (31/32) (julio/diciembre 1992); Moctezuma. Apogeo y caída del imperio azteca, trad. Tessa Brisac (México: Ediciones Era, INAH, 2014), 235-252, 279-284; Patrick K. Johansson, "Presagios del fin de un mundo en textos proféticos nahuas”, Estudios de Cultura Náhuatl (45) (enero-junio 2013); Miguel LeónPortilla, "Profecías y portentos en vísperas de la conquista", en Ideas y presagios del descubrimiento de América, comp. Leopoldo Zea (México, Instituto Panamericano de Geografía e Historia, Fondo de Cultura Económica, 1991); Guilhem Olivier, Tezcatlipoca. Burlas y metamorfosis de un dios azteca, trad. Tatiana Sule (México: Fondo de Cultura Económica, 2004), 246-249; Pastrana, Historias de la Conquista. Aspectos de la historiografia de tradición náhuatl, Serie Teoría e Historia de la Historiografía 2 (México: Universidad Nacional Autónoma de México, Instituto de Investigaciones Históricas, 2009), 31-63.

${ }^{12}$ Véase Carlos Santamarina Novillo, "El sistema de dominación azteca: el imperio tepaneca" (Tesis de doctorado, Universidad Complutense de Madrid, 2005), 281.

${ }^{13}$ Fray Toribio de Benavente (Motolinía), Memoriales (Libro de oro, MS JGI 31), Biblioteca Novohispana 3, ed. Nancy Joe Dyer, cap. xLIx, 311 (México: El Colegio de México, Centro de Estudios Lingüísticos y Literarios, 1996). 
versalistas ${ }^{14}$ confirmadas por la historia y la narración bíblica. De esta manera, da como ejemplo de ello la ruina de Jerusalén y de su templo para luego aplicar dichas señales divinas a la realidad indígena, específicamente a la Conquista. ${ }^{15}$ Aunque Benavente no tiene la intención de hacer pasar el significado de los augurios como propios de la tradición nahua, no cabe duda que el franciscano supo identificar los paralelismos que existían entre las tradiciones judeocristiana y nahua respecto a aquéllos. Basta leer otro fragmento de la obra de Benavente en la que claramente consigna la interpretación augural nahua del temblor bajo semejantes términos: "el temblor de la tierra hera señal que se auía presto de acabar el maýz de las troxes". ${ }^{16}$ O también podemos ver corroborados los significados del cometa en otras fuentes documentales: en el año nahui acatl ("cuatro caña"), 1535, se registró un cometa y la muerte de un señor indígena. Dos años después, en chicuace calli ("seis casa"), los negros de la ciudad de México se sublevaron y sus líderes fueron ahorcados. También se registró un cometa y un gran temblor. ${ }^{17}$ Posteriormente, en chicome tochtli ("siete conejo"), 1538, mucha gente murió de viruela; y un año después apareció un cometa. ${ }^{18}$ Asimismo, dijeron los nahuas que cuando los animales eran muertos por el golpe de un cometa o "flechados" por éste se agusanaban, lo que hacía que fueran vistos con temor y mucho asco. ${ }^{19}$

Los fenómenos naturales considerados tetzahuitl como fueron los terremotos, los eclipses, los cometas y otro tipo de señales celestes y terrestres extraordinarias, reflejan un aspecto fundamental de la idea que tuvieron los nahuas de la historia: ésta era cíclica. Dicho

${ }^{14}$ León-Portilla, "Profecías y portentos", 71.

${ }^{15}$ Benavente, Memoriales, cap. XLIx, 311.

${ }^{16}$ Benavente, Memoriales, cap. XLIII, 280.

${ }^{17}$ CTR, parte III, lám. xxxi, 320.

${ }^{18}$ Ibid., lám. XxxiI, 322.

${ }^{19}$ Fray Bernardino de Sahagún, Augurios y abusiones, Serie Cultura Náhuatl, Fuentes: 7, ed. Alfredo López Austin, 151 (México: Universidad Nacional Autónoma de México, Instituto de Investigaciones Históricas, 1969); Primeros Memoriales, ed. Thelma Sullivan, completado, revisado y con adiciones por H. B. Nicholson cap. II, fol. 282r, párr. 1, 155 (Norman: University of Oklahoma, 1997). 
carácter permitía pensar los eventos como tipos de repeticiones. Así como los eclipses y terremotos intervinieron en la destrucción de algunos Soles o edades pasadas, de igual manera iban a hacerse presentes en la destrucción de la era presente. ${ }^{20}$

De acuerdo al día del calendario ritual o tonalpohualli, determinada fuerza divina ejercía su influencia sobre la Tierra, ya fuera nefasta o benigna; dicha fuerza, cumplido el ciclo calendárico, volvía a intervenir. Visto así, los eventos presentes eran interpretados a partir de patrones establecidos por el pasado; y éste, a su vez, se ajustaba a las circunstancias presentes. Asimismo, a partir del conocimiento del pasado se podía anticipar el futuro. ${ }^{21}$

Otra característica del pensamiento histórico prehispánico implícita en el párrafo anterior es la intervención de la divinidad en cada uno de los acontecimientos humanos. En palabras de Miguel Pastrana, ${ }^{22}$ "La irrupción de lo maravilloso es parte de la mecánica misma de la historia, la acción de los dioses no es algo ajeno al mundo, sino que es parte integral de su dinámica y de su naturaleza”. En este sentido, la narración de los acontecimientos consistió en un entrelazamiento de historia y mito. Los tetzahuitl, precisamente, fueron una de las manifestaciones de lo sagrado en el ámbito huma-

${ }^{20}$ Fernando de Alva Ixtlilxochitl, Sumaria relación de todas las cosas que han sucedido en la Nueva España, y de muchas cosas que los tultecas alcanzaron y supieron desde la creación del mundo, hasta su destrucción y venida de los terceros pobladores chichimecas, hasta la venida de los españoles, sacada de la original historia de esta Nueva España, en Obras Históricas, tomo I, ed. Edmundo O'Gorman, 264-265 (Toluca: Instituto Mexiquense de Cultura, Universidad Nacional Autónoma de México, Instituto de Investigaciones Históricas, 1997a); Anales de Cuauhtitlan, 5; CTR, parte III, lám. 33r, 277; "Histoyre du Mechique”, cap. vi, 145; Diego Muñoz Camargo, Historia de Tlaxcala (Ms. 210 de la Biblioteca Nacional de París), ed. Luis Reyes García, colaboración de Javier Lira Toledo, 164 (México: Gobierno del Estado de México, Ciesas, Universidad Autónoma de Tlaxcala, 1998).

${ }^{21}$ Emily Good Umberger, "Antiques, Revivals, and References to the Past in Aztec Art”, RES, Anthropology \& Aesthetics (13) (1987): 63; León-Portilla, "Profecías y portentos", 80; León-Portilla, "Las profecías del encuentro. Una apropiación mesoamericana del otro", en De palabra y obra en el Nuevo Mundo. 2. Encuentros interétnicos, ed. Manuel Gutiérrez Estévez, Miguel León-Portilla, Gary H. Gossen y J. Jorge Klor de Alva, 232 (México: Siglo XXI, 1992); Johansson, "Presagios del fin", 72, 90; Cortés, "Motecuzo$\mathrm{ma} /$ Huemac", 26, 31.

${ }^{22}$ Pastrana, Historias de la Conquista, 63. 
no, formaron parte de "un sistema de comunicación entre los hombres y los dioses". ${ }^{23}$

Pastrana ${ }^{24}$ ha profundizado en varios trabajos sobre la concepción nahua del tetzahuitl o presagio. Una de las definiciones que ha propuesto es la siguiente:

cierta forma de manifestación de los dioses nahuas en el ámbito de lo humano, que rompe el orden habitual y cotidiano del mundo para anunciar y provocar acontecimientos futuros generalmente de carácter negativo; por ello suelen causar temor, espanto y asombro. Los tetzahuitl acontecen de igual manera en el transcurso del ciclo de vida de los más humildes macehuales, o en los cambios políticos, sociales e históricos de mayor envergadura y trascendencia. En el primer caso pueden ser relativamente sencillos, como la infestación de ratones en una casa común que pueden anunciar la enfermedad y la muerte de sus ocupantes, mientras que en el segundo caso son imponentes, como la aparición de un fuego en el cielo nocturno de forma piramidal que se observa durante semanas, ${ }^{25} \mathrm{el}$ cual prefigura la destrucción de ciudades enteras. ${ }^{26}$

El tetzahuitl era, por naturaleza, un fenómeno de significado ambiguo. Su presencia podía pronosticar una serie de desgracias, pero sólo era posible conocer a ciencia cierta su significado cuando había ocurrido algo que pudiera relacionarse con él. Esta característica intrínseca del presagio nos conduce directamente a la construcción del acontecimiento. Una vez transcurrido el evento, éste pasaba por un proceso de interpretación a la luz de los resultados presentes, donde la aparición de una señal portentosa cobraba sentido. En el caso de la Conquista, los tetzahuitl que la vaticinaron sólo fueron interpretados de tal manera una vez consumada la destrucción de

${ }^{23}$ Miguel Pastrana, "Los presagios de la conquista como forma de conciencia histórica”, en Estudios Michoacanos VIII, coord. Bárbara Skinfill Nogal y Alberto Carrillo Cázares, 131 (Zamora: El Colegio de Michoacán, Instituto Michoacano de Cultura, 1999).

${ }^{24}$ Pastrana, "Los presagios de la conquista"; Historias de la Conquista; "La idea de tetzahuitl en la historiografía novohispana”, Estudios de Cultura Nábuatl (47) (enero-junio): 2014.

${ }^{25}$ Trataremos este augurio en el último apartado del texto.

${ }^{26}$ Pastrana, "La idea de tetzahuitl", 239. 
Tenochtitlan. ${ }^{27}$ Lo anterior nos puede llevar a pensar con facilidad que la información de los augurios de la Conquista fue manipulada por los cronistas novohispanos, ya fueran españoles o indígenas cristianizados, y que no puede ser considerada como propiamente indígena. ${ }^{28}$ No obstante, advierte Miguel Pastrana, ${ }^{29}$ los "portentos tienen una significación dentro de la tradición cultural náhuatl, no se trata de presagios copiados del cristianismo o de la antigüedad clásica. Su tratamiento ciertamente puede revelar toques cristianos, pero el núcleo del significado está en la tradición religiosa náhuatl". Trataré darle fuerza a dicha afirmación en el último apartado de este texto, justamente cuando aborde la información de los seres de características sobrehumanas que vendrían a conquistar las tierras americanas, tal como lo asentaron fray Diego Durán ${ }^{30}$ y Hernando Alvarado Tezozómoc. ${ }^{31}$

La crítica de fuentes aplicada a las crónicas nos permite reconocer la ideología y los intereses del autor, así como la manipulación que llevó a cabo de la información y las influencias a que se vio expuesta provenientes de fuentes bíblicas, clásicas o medievales. Por otro lado, igualmente permite identificar la información proveniente de la tradición indígena. El caso de la obra del historiador acolhua Fernando de Alva Ixtlilxóchitl es ejemplar respecto a lo anterior. Se ha advertido que Ixtlilxóchitl expuso en su obra una visión providencialista de la historia amerindia, en la cual el Dios cristiano es quien orienta los acontecimientos. Así, la conquista se ve como un evento ineludible determinado por Dios y como una prolongación de la historia indígena. ${ }^{32}$ Efectivamente, los intereses ideológicos del texcocano mantuvieron concordancia con los intereses religiosos

${ }^{27}$ Pastrana, "Los presagios de la conquista”, 131; “La idea de tetzahuitl”, 24, 30.

${ }^{28}$ Véase Georges Baudot, "Alteridad y monstruosidad: el enfrentamiento de los modelos culturales", Cuadernos Americanos, Nueva-época, año vi 6(36) (noviembre-diciembre 1992): 54-55.

${ }^{29}$ Pastrana, Historias de la Conquista, 53.

${ }^{30}$ Durán, Historia de las Indias, tomo I, tratado I, cap. LXx, 584.

${ }^{31}$ Crónica Mexicana, notas de Manuel Orozco y Berra (México: Editorial Leyenda, 1944), cap. CVII, 525; cap. CIX, 528.

${ }^{32}$ Georges Baudot, "Nezahualcóyotl, príncipe providencial en los escritos de Fernando de Alva Ixtlilxóchitl”, Estudios de Cultura Náhuatl (25) (1995): 23-25. 
coloniales. Desde su posición de mestizo católico, Ixtlilxóchitl rechazó la religión prehispánica, por lo que debemos de ser cautos al utilizar la información que proporciona sobre aquélla. ${ }^{33}$ Un buen ejemplo de la manipulación del acolhua de la información religiosa prehispánica es el cerro del Tetzcutzinco, un complejo arquitectónico dispuesto por Nezahualcóyotl que contaba con acueductos, canales y fuentes de agua, así como con jardines. En su obra, el historiador acolhua omitió cualquier contenido religioso del Tetzcutzinco, pero la arqueología ha revelado la importancia del cerro como un lugar de purificación y de culto a las deidades de la lluvia y la fertilidad. ${ }^{34}$ Sin embargo, hay que recordar que Alva Ixtlilxochitl perteneció a la nobleza texcocana y que tenía acceso a fuentes indígenas prehispánicas. De este modo, "podemos considerar su información histórica válida, aunque la estructura en la que está escrita sea europea" ${ }^{35}$

\section{LA CAÍDA DE TOLlaN}

Según Alva Ixtlilxóchitl, ${ }^{36}$ los augurios de la caída de Tollan comenzaron cuando el sacerdote Huémac predijo el nacimiento de un nińo que habría de heredar el reino, quien sería favorecido por unos y rechazado por otros, y que nacería con ciertas señales en su cuerpo, siendo la principal tener los cabellos crespos, con los cuales se formaría una tiara sobre su cabeza. Dicha seña lo acompañaría hasta la muerte. Huémac señaló que por un tiempo sería un gobernante sabio y justo, pero pasado el tiempo se volvería "necio y desventurado", y que por cuya causa los de su ciudad habían de perecer con grandes castigos del cielo. En el año ce tecpatl ("uno pedernal"), precisa el historiador, se revelarían algunos hombres de su mismo linaje

${ }^{33}$ Michel R. Oudijk, "La toma de posesión: un tema mesoamericano para la legitimación del poder", Relaciones Estudios de Historia y Sociedad XXIII(91) (verano 2002): 102, nota 3 .

${ }^{34}$ Patrick Lesbre, "El Tetzcutzinco en la obra de Fernando de Alva Ixtlilxóchitl. Realeza, religión prehispánica y cronistas coloniales”, Estudios de Cultura Náhuatl (32) (2001): 333, 335-336.

${ }^{35}$ Michel R. Oudijk, "La toma de posesión”, 102, nota 3.

${ }^{36}$ Fernando de Alva Ixtlilxóchitl, Sumaria relación, tomo I, 271. 
y le harían la guerra, lo que provocaría la muerte de la mayor parte de la población tolteca.

La seña física que caracterizaría al nińo trae a la memoria la cabellera de Tlaltecuhtli y de Mictlantecuhtli, entre otras divinidades, quienes también tenían una cabellera rizada tal como se muestra en la escultura y en códices. ${ }^{37}$ "Este rasgo distingue a las temibles divinidades de la noche, la tierra, el inframundo y la muerte, pues es la antítesis del canon estético mexica que calificaba al pelo lacio como signo de belleza" ${ }^{38}$ Los nahuas pudieron atribuirle al cabello crespo ideas de muerte y destrucción, de tal manera que este rasgo en el niño -quien se identifica con Quetzalcóatl, como se verá más adelante- vaticinaba la ruina de su pueblo y su ciudad.

Algunos ańos antes de la destrucción de Tollan, continuaba la profecía de Huémac, también habrían de aparecer señales de una inversión del orden en los ámbitos natural y humano, que muestran al mismo tiempo los excesos en dichos ámbitos: al conejo le saldrían cuernos como el venado; el huitzitzilin o colibrí poseería espolón; y las mujeres nobles tendrían relaciones sexuales con los sacerdotes de los templos. Ante tales ofensas, Tloque Nahuaque se enojaría con ellos y los castigaría con "rayos, granizos, hielos, hambres, sabandijas $\mathrm{y}$ otras persecuciones del cielo, $\mathrm{y}$ después de todo esto, con guerras, con que se acabarían de todo punto unos con otros". ${ }^{39}$

La información anterior recuerda los augurios que evidenciaron las faltas de los purépechas de Hetúquaro frente al servicio a sus dioses:

y empenzaron los árboles, de [en blanco] aun hasta chiquitos, de tener fruto que las ramas apesgaban hacia tierra; y empenzaron los maguéis, aun

${ }^{37}$ En el gran monolito mexica de Tlaltecuhtli encontrado en 2006 se aprecia muy bien la cabellera ondulada de la deidad de la tierra, véase Leonardo López Luján, Tlaltecuhtli (México: Fundación Conmemoraciones 2010, Sextil Editores, Instituto Nacional de Antropología e Historia, 2010), 74-75, 92.

${ }^{38}$ Leonardo López Luján, Tlaltecuhtli, 77; véase fray Bernardino de Sahagún, Florentine Codex, ed. Charles E. Dibble y Arthur J. O. Anderson, lib. II, cap. xxIv, 66 (Santa Fe: The School of American Research, The University of Utah, 1950-1983), A partir de aquí, $C F$.

${ }^{39}$ Fernando de Alva Ixtlilxóchitl, Sumaria relación, tomo I, 271. 
hasta los chiquitos, de echar en medio másteles largos que parescían maderos. Y empezaron hasta las mochachas pequeñas de empreñarse, que aún no habían dejado la niñez y tenían ya las tetas grandes como mujeres [...] $\mathrm{Y}$ empezaron las mujeres mayores de parir piedras de navajas. ${ }^{40}$

En idénticos términos señala el mismo documento los vaticinios de la Conquista: "que los cerezos aun hasta los chiquictos, habían de tener fruto, ${ }^{41}$ y los maguey[e]s pequeños habían de echar mástiles. Y las niñas que se habían de empreñar antes que perdiesen la niñez" ${ }^{42}$

Tal como ha afirmado Miguel Pastrana, "Los trastornos en el orden natural de las cosas son anuncios de los grandes males y cambios políticos porque ambos se corresponden con los cambios en el orden de lo divino. Todo cambio radical entre los hombres será anunciado por la alteración profunda de la naturaleza, porque, en última instancia ambos son reflejo de lo que pasa entre los dioses". ${ }^{43}$

Regreso a la información sobre los días postreros de Tollan. Aquel de quien se había profetizado era Quetzalcóatl, llamado en la obra de Ixtlilxóchitl, Meconetzin, "hijito de maguey" y, por otro nombre, Topiltzin. ${ }^{44}$ Después de gobernar cuarenta años empezaron las señales que Huémac había pronosticado. Y precisamente en los últimos ańos de ese periodo Topiltzin cometió graves faltas, que fueron imitadas por los de su ciudad y sus provincias. ${ }^{45}$

Pasado el tiempo, Quetzalcóatl volvió a ser la persona recta y sabia de antes. Vio los augurios que le habían pronosticado a su padre y sintió gran pena, pues, eran signo de su destrucción. Después les indicó a sus sacerdotes que se debían hacer ceremonias y sacrificios a las deidades para aplacar su ira. Al siguiente año, en ce calli ("uno

${ }^{40}$ Jerónimo de Alcalá, Relación de Michoacán, estudio introductorio, Jean-Marie G. Le Clézio, II parte, cap. xxII, f. 111, 112-113 (Zamora: Michoacán, El Colegio de Michoacán, 2008),

${ }^{41}$ El dato omitido en los augurios mostrados a los purépechas de Hetúquaro puede completarse con la información de los augurios de la Conquista asentada en la misma Relación de Michoacán: corresponde a árboles de cerezos.

${ }^{42}$ Ibid., III parte, cap. XXII, f. 41v, 244.

${ }^{43}$ Pastrana, "Los presagios de la conquista", 139.

${ }^{44}$ Fernando de Alva Ixtlilxóchitl, Sumaria relación, tomo I, 275.

${ }^{45}$ Ibid., 277; véase también CVL 3738, lám. viII, 26. 
casa”), los dioses comenzaron a castigar al pueblo tolteca "enviándoles grandísimos aguaceros, huracanes y sapos del cielo, que les destruía la mayor parte de sus edificios, lloviendo casi cien días sin cesar, lo cual ellos entendieron que el mundo se quería acabar con otro diluvio". Al año siguiente, ome tochtli ("dos conejo"), "vino una grandísima calor y seca, que se secaron todas las plantas y árboles". ${ }^{46}$ Los Anales de Cuauhtitlan ${ }^{47}$ señalan que en el ańo chicome tochtli ("siete conejo") hubo siete años de mucha hambre y muerte, y por eso se dice que los toltecas se sieteaconejaron.

Algunos acontecimientos que anunciaron la caída de Tollan vaticinaban al mismo tiempo un regreso a los orígenes. Entonces, la destrucción del tiempo presente implicaba un retorno al tiempo mítico. En un mito mesoamericano citado por Alfredo López Austin, ${ }^{48}$ el conejo poseía hermosos cuernos en forma de ramas, pero se los prestó al ciervo, quien, mediante engaños, se quedó con ellos hasta el momento final de la creación. En consecuencia, los conejos no poseen cuernos mientras que los ciervos tienen la cabeza adornada. Todos los seres adquieren sus características definitivas al final de la aventura mítica. De esta manera, con base en el mito anterior, se puede concluir que el vaticinio del conejo que desarrollaría cuernos como los del venado rememoraba el tiempo primigenio en el que los animales todavía no adquirían sus rasgos últimos.

La caída de sapos del cielo que ocasionaría, junto con otros eventos, la destrucción de sus edificios, trae a la memoria un acontecimiento igualmente mítico. Posterior al diluvio, y antes de la era tolteca, los hombres emprendieron la tarea de construir una gran pirámide -en algunas versiones corresponde a la de Cholollan- para evitar la ruina si llegaba a ocurrir otra inundación. Durante el proceso, cuenta una de las versiones, una gran piedra en figura de sapo cayó del cielo. Este hecho los aterrorizó por tenerlo por mal agüero, e inmediatamente la edificación cesó. ${ }^{49}$ De acuerdo con el $C V L$

${ }^{46}$ Fernando de Alva Ixtlilxóchitl, Sumaria relación, tomo I, 278.

${ }^{47}$ Anales de Cuaubtitlan, 13.

${ }^{48}$ Alfredo López Austin, "Los animales como personajes del mito", Arqueología Mexicana vi(35) (enero-febrero 1999), 51.

${ }^{49}$ Fray Gerónimo de Mendieta, Historia eclesiástica indiana, tomo I, lib. II, cap. VIII, 
$3738,{ }^{50}$ la pirámide fue destruida por un chalchihuitl que provino del cielo, mientras que para otros dicha piedra se convirtió en sapo.

Tanto el numeral como los signos del tonalpohualli (calendario adivinatorio), que en su conjunción conformaban las fechas calendáricas, contagiaban en un determinado tiempo su esencia sobre la Tierra. Todas las fechas del calendario tenían una carga positiva y negativa, pero generalmente se inclinaban hacia una de las dos. Este aspecto mantiene correspondencia con una de las concepciones fundamentales de la cosmovisión de los nahuas: la ambivalencia de significado. La esencia de los días ozomatli o mono, por ejemplo, generalmente se mostraba favorable, pero el mal comportamiento de la persona que había nacido bajo tal signo de día hacía que su destino fuera desfavorable. ${ }^{51}$ Las fechas calendáricas en que ocurrieron las desgracias que asolaron a los toltecas parecieran no ser fortuitas. Algunos de los significados del signo tecpatl (pedernal) eran la esterilidad ${ }^{52}$ y la guerra. ${ }^{53}$ El signo calli (casa), por estar relacionado con el occidente, también era considerado de gran infortunio. ${ }^{54}$ Asimismo, cuando llegaba el año ce tochtli, que indicaba el inicio de un nuevo ciclo, dijeron los informantes nahuas de Sahagún, "se tenía mucho miedo, se expresaba angustia, se mostraba congoja, porque en éste [ańo] había hambruna"'55 [cenca nemaubtiloya, tlatemmachoya, netemmachoa: ipampa, in ipan muchihuaya mayanaliztli]..$^{56} \mathrm{La}$

ed. Antonio Rubial García, 194 (México: Consejo Nacional para la Cultura y las Artes, Cien de México, 2002). Véanse Fernando de Alva Ixtlilxóchitl, Sumaria relación, tomo I, 263; Mariano Veytia, Historia antigua de México tomo I, lib. I, cap. II (México: Editorial Leyenda, S. A., 1944), 12.

${ }^{50}$ CVL 3738, lám. XIV, 38.

${ }^{51}$ Jaime Echeverría García, "Entre la fertilidad agrícola y la generación humana: el rol fecundante del mono entre los antiguos nahuas", Estudios de Cultura Nábuatl (50) (julio-diciembre, 2015): 209, 247.

${ }^{52}$ Fray Diego Durán, Historia de las Indias, 237. Los otomíes igualmente tenían al año pedernal "por estéril y enfermo", Francisco Ramos de Cárdenas, "Relación de Querétaro”, Relaciones geográficas del siglo XVI: Michoacán, vol. 9, ed. René Acuña, 238 (México: Universidad Nacional Autónoma de México, Instituto de Investigaciones Antropológicas, 1987).

${ }^{53}$ CVL 3738, lám. xIv, 42.

${ }^{54}$ Fray Diego Durán, Historia de las Indias, tomo II, tratado III, cap. I, 228.

${ }^{55}$ Traducción propia, excepto cuando no se indique.

${ }^{56} \mathrm{CF}$, lib. vII, cap. vII, 21-22. 
expresión "se sieteaconejaron" aplicada a los toltecas quiere decir que la esencia del año chicome tochtli ("siete conejo") poseyó a dicho pueblo con su valencia de hambruna, lo que les hizo padecer hambre.

El número de años que padecieron hambre los toltecas tampoco es casualidad. Así como ocurrió con el signo pedernal, que en los códices y en el mito ${ }^{57}$ conserva un simbolismo sexual y de procreación, pero que en otros contextos tiene un significado de muerte, el número siete también cargó con una ambivalencia de sentido. $\mathrm{Al}$ pertenecer a Chicomecóatl y ser ella la diosa de los mantenimientos, el numeral era de carácter auspicioso. ${ }^{58}$ Sin embargo, algunas fuentes afirman que esta deidad también simbolizaba la esterilidad y la hambruna. ${ }^{59}$ Por lo tanto, al estar vinculado con Chicomecóatl en su aspecto destructivo, el número siete vino a redondear el signo tochtli y provocar una larga esterilidad de los campos y hambre.

El pronóstico de los signos de año y su corroboración en los acontecimientos constituyó una base sólida de interpretación de los eventos pasados y presentes. Si uno de los significados de los años conejo, pedernal, casa, y del numeral siete, tenía que ver con la hambruna, la esterilidad y el infortunio, tal como lo concibieron los mexicas, era lógico suponer que en la reconstrucción de los hechos de los días previos a la destrucción de Tollan, dichos signos de año hubieran vaticinado semejantes desgracias.

La narración del historiador acolhua continúa diciendo que posteriormente cayeron heladas. Rayos y granizos destruyeron en abundancia árboles y construcciones. Después de casi 12 años de alivio, cuando la tierra empezaba a fructificar de nuevo, se vio arrasada por plagas de langostas y gusanos. De igual manera acontecieron fuertes guerras con los señores herederos. ${ }^{60}$

${ }^{57}$ CVL 3738, lám. xv, 45; fray Gerónimo de Mendieta, Historia eclesiástica indiana, tomo I, lib. II, cap. I, 181.

${ }^{58}$ Fray Bernardino de Sahagún, Historia general de las cosas de la Nueva España, tomo I, lib. Iv, cap. xv, ed. Alfredo López Austin y Josefina García Quintana, 379 (México: Consejo Nacional para la Cultura y las Artes, Cien de México, 2002).

${ }^{59}$ Fray Diego Durán, Historia de las Indias, tomo II, tratado II, cap. XIV, 141-142; CVL 3738, lám. xvi, 48; CTR, parte II, lám. I, 178.

${ }^{60}$ Fernando de Alva Ixtlilxóchitl, Sumaria relación, tomo I, 278. 
En la versión de fray Juan de Torquemada ${ }^{61}$ tras haber sido perseguidos y oprimidos por varios gobernantes, los toltecas infirieron que tales desgracias eran producto del enojo que les habían causado a sus dioses. Por ello, decidieron reunirse los sacerdotes y nobles en Teotihuacan para hacerles fiesta y ganar su agrado. Durante la celebración, en medio de la gente se apareció un gigante de brazos largos y delgados, quien comenzó a bailar con ellos. Mientras bailaba, todo aquel al que abrazaba moría entre sus brazos. Otro día se les apareció Tezcatlipoca en figura de otro gigante, y "con las manos y dedos de ellas muy largos y ahusados y bailando con ellos los fue ensartando en ellos; $y$ de esta manera hizo el demonio aquel día gran matanza de ellos". Hay que recordar que una de las apariciones nocturnas que señalaron los informantes de Sahagún fue la de un gigante, que precisamente era una advocación de Tezcatlipoca. ${ }^{62}$

Según la Leyenda de los Soles, ${ }^{63}$ cuando comenzaron los agüeros de la caída de Tollan, los toltecas "vieron un bulto de ceniza con forma humana, un gigante; y era él quien se comía la gente" [ye quitta in tlacanexquimilli in tlacahueyac; auh niman ya yehuatl in aquin tequaya]. Posiblemente también se tratara del mismo dios.

Los últimos augurios antes del fin de la ciudad fueron la aparición de un venado que arrastraba su cola por el suelo, eclipses de sol y de luna y cometas. ${ }^{64}$ En su Memorial breve..., Chimalpain ${ }^{65}$ afirmó que "una estrella que humeó sobre el pueblo de Tullan fue por lo que se escandalizaron los tulteca" [cecitlalli popocac yn ipan altepetl

${ }^{61}$ Fray Juan de Torquemada, Monarquía Indiana de los veinte y un libros rituales y monarquí indiana, con el origen y guerras de los indios occidentales, de sus poblazones, descubrimiento, conquista, conversión y otras cosas maravillosas de la mesma tierra, Serie de Historiadores y Cronistas de Indias 5, tomo I, lib. I, cap. XIV, edición preparada por el Seminario para el Estudio de Fuentes de Tradición Indígena, bajo la coordinación de Miguel León-Portilla, 56-57 (México: Universidad Nacional Autónoma de México, Instituto de Investigaciones Históricas, 1975).

${ }^{62} \mathrm{CF}$, lib. v, cap. XII: 175 .

${ }^{63}$ Leyenda de los Soles, 192-194.

${ }^{64}$ Fernando de Alva Ixtlilxóchitl, Sumaria relación, tomo I, 283-284.

${ }^{65}$ Domingo Francisco de San Antón Muñón Chimalpain Cuauhtlehuanitzin, $M e-$ morial breve acerca de la fundación de la ciudad de Culhuacan, Fuentes 9, ed. Víctor M. Castillo F., 14-15 (México: Universidad Nacional Autónoma de México, Instituto de Investigaciones Históricas, Serie de Cultura Náhuatl, 1991). 
Tullam. Ynic motetzahuique Tulteca]. Ulteriormente, prosigue Ixtlilxóchitl, se llevó a cabo una cruenta batalla que provocó la diáspora tolteca al quedar disuelto el imperio. ${ }^{66} \mathrm{La}$ conjunción de tales eventos naturales extraordinarios no pudo sino significar la pronta destrucción de Tollan. ${ }^{67}$

Los acontecimientos desastrosos que padecieron los toltecas debido a las transgresiones de Quetzalcóatl, coinciden con los castigos que lanzaba la divinidad contra una determinada ciudad motivados por la desobediencia de su gobernante. Éstos consistían en discordias al interior del reino, hambre, pestilencias, invasión de enemigos, y finalmente su destrucción. ${ }^{68}$ Tales puniciones se concibieron como la materialización del enojo del dios.

Aunque en la versión acolhua no se señala quienes serían los que vendrían a sustituir en el poder a los toltecas, los mexicas se encargaron de situarse como los detentadores del linaje tolteca, con sus debidas innovaciones. Según la Leyenda de los Soles, ${ }^{69}$ cuando terminaron los cuatro ańos de hambruna que habían asolado a Tollan, a través de un tolteca los tlaloque le anunciaron a Huémac que "ya va a perecer el tolteca, pues ya prevalecerá el mexica" [ye pollohuiz in toltecatl, ca ye onoz in mexicatl].

Como acabamos de ver, la aparición de tetzahuitl materializados tanto en señas celestes portentosas como en figuras sobrehumanas igualmente maravillosas (los gigantes), fueron interpretadas a posteriori como augurios de la ruina de una entidad política. Si bien cada fenómeno celeste inusual tuvo un significado preciso -o medianamente preciso-, su conjunción, aunado a otro tipo de desgracias como hambrunas, guerras y epidemias, vaticinaba acontecimientos de gran relevancia como el cambio del poder político y la imposición de nuevos dominios. Estos desafortunados acontecimientos fueron motivados por la cólera de los dioses frente a las transgresiones del gobernante. Quetzalcóatl cometió "pecados muy graves"

${ }^{66}$ Ibid., 284.

${ }^{67}$ En el siguiente apartado expongo con detenimiento los significados del eclipse solar y del cometa.

${ }^{68}$ Fray Bernardino de Sahagún, Historia general, tomo II, lib. vi, cap. x, 517.

${ }^{69}$ Leyenda de los Soles, 195-197. 
según la versión de Ixtlilxóchitl; ${ }^{70}$ pero otras fuentes precisan que se embriagó y cometió actos sexuales indebidos. ${ }^{71}$ Estos tres elementos: manifestación de tetzahuitl, transgresiones del gobernante y anuncio de un nuevo orden político, antecedieron al derrumbe del poderío tepaneca y a la destrucción de Tenochtitlan, como veremos a continuación.

\section{LA CAÍDA DEL IMPERIO TEPANECA}

Nuestra principal fuente para conocer la hegemonía que ejercieron los tepanecas en el Valle de México durante el Posclásico es sin duda la obra histórica de Fernando de Alva Ixtlilxóchitl. El inconveniente de ello es que fue escrita desde el punto de vista acolhua; y esto forzosamente repercutió en la manera de concebir a los tepanecas y a sus principales dirigentes, Tezozómoc y Maxtla, su hijo. Si bien era común en la dinámica histórica del Valle de México en el Posclásico, que los altepetl lucharan por ganar mayor poder político a través de la conquista, los deseos de Tezozómoc y, posteriormente, de Maxtla, de extender su dominio sobre las ciudades acolhuas y otras más les ganaron el adjetivo de "tiranos" en la obra de Ixtlilxóchitl. Contamos también con otras fuentes que igualmente transmiten la visión acolhua como son el Códice Xólotly la Monarquía Indiana... de fray Juan de Torquemada. ${ }^{72}$

Más allá de elaborar una reconstrucción de los acontecimientos previos a la destrucción del imperio tepaneca y del proceso de liberación de Tenochtitlan y de otros altepetl de su yugo, ${ }^{73}$ me interesa dar cuenta del modelo mítico-histórico de tradición nahua que explicó el fin del poder tepaneca. ${ }^{74}$ La versión acolhua de los hechos me es especialmente útil para dicho fin.

${ }^{70}$ Fernando de Alva Ixtlilxóchitl, Sumaria relación, tomo I, 277.

${ }^{71}$ Anales de Cuauhtitlan, 9-10; fray Diego Durán, Historia de las Indias, tomo II, tratado II, cap. I, 23.

${ }^{72}$ Carlos Santamarina Novillo, "El sistema de dominación”, 546.

${ }^{73}$ Véase Ibid., 553-598.

${ }^{74}$ Véase Clementina Battcock, "Aspectos simbólicos, representaciones y significaciones de las diferentes muertes de Maxtla: una propuesta de análisis", Estudios de Cultura Nábuatl (40) (2009). 
Con el asesinato del tlatoani acolhua Ixtlilxóchitl, instigado por Tezozómoc, se inicia el periodo de supremacía tepaneca en el Valle de México en manos suyas. Y con el fin de asegurar su dominio, decidió acabar con la estirpe reinante acolhua, Nezahualcóyotl. De esta manera, la hegemonía tepaneca se caracterizó por su persecución. Al morir Tezozómoc, su hijo Maxtla retomó dicha tarea. Las faltas que cometió aquél para ganar poder, y, posteriormente, su vástago, fue uno de los elementos que detonó el fin del imperio tepaneca. Es más, Tezozómoc vivió con miedo de que Nezahualcóyotl recuperara su gobierno y lo destruyera. Una vez sońó que éste se le aparecía en forma de águila, la cual le desgarraba y comía a pedazos el corazón; otra vez lo soñó convertido en jaguar, que le despedazaba los pies. También soñó que un lobo y una víbora grande lo devoraban. Esto provocó que despertara lleno de espanto. ${ }^{75}$

Durante el tiempo que duró la persecución de Nezahualcóyotl, asienta Alva Ixtlilxóchitl, ${ }^{76}$ "hubo muchos prodigios y señales". "En el cielo hubo cometas y eclipse del sol y otras señales; en la tierra se vieron muchos monstruos". Estos signos augurales sin lugar a dudas vaticinaron un cambio de situación política. ${ }^{77}$ En Chiauhtla, territorio aculhua, se les apareció a Tlazacuilotzin y Tlacpanhuehuetzin "un monstruo a gatas, con un pie y dos manos como de persona, y la cara ni más ni menos muy feísima, y unos cabellos que le cubrían el cuerpo tan gruesos y tan anchos como un dedo grande y el cuerpo tan grueso como de dos brazas". Aterrorizados, mientras más lo repelían más se les acercaba. De acuerdo con Ixtlilxóchitl, ${ }^{78}$ éste les dijo: "Mirad, Tlaxcala, Huexutzinco, Tula y otras partes, vienen sobre vosotros;

${ }^{75}$ Anales de Cuauhtitlan, 38; Fernando de Alva Ixtlilxóchitl, Sumaria relación, tomo I, 349; Historia de la nación chichimeca, en Obras históricas, tomo II, cap. xxI, ed. Edmundo O'Gorman, 54 (Toluca: Instituto Mexiquense de Cultura, Universidad Nacional Autónoma de México, Instituto de Investigaciones Históricas, 1997c).

${ }^{76}$ Fernando de Alva Ixtlilxóchitl, Sumaria relación, tomo I, 370.

${ }_{77}$ Patrick Lesbre, "Nezahualcóyotl, entre historia, leyenda y divinización”, en El héroe, entre el mito y la historia, coord. Federico Navarrete y Guilhem Olivier, 25 (México: Universidad Nacional Autónoma de México, Centro de Estudios Mexicanos y Centroamericanos, 2000).

${ }^{78}$ Fernando de Alva Ixtlilxóchitl, Sumaria relación, tomo I, 370. 
Figura I. Ser monstruoso de un pie y dos brazos y de abundante pelo

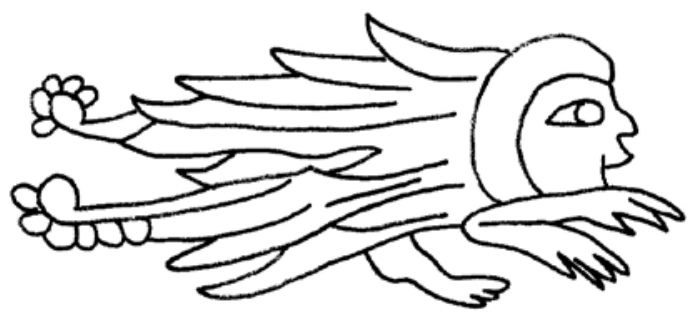

Fuente: Códice Xolotl, lám. Ix, c-2. Dibujo de Jaime Echeverría.

Figura 2. Lobo con patas de palo

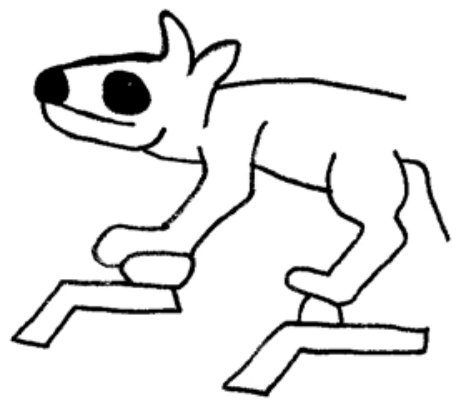

Fuente: Códice Xolotl, 1950, lám. x, c-3. Dibujo de Jaime Echeverría.

el tirano Maxtla se acabará, y recobrará al que le viene de derecho" ${ }^{79}$ En otra ocasión, un capitán tepaneca se encontró con un lobo con patas de palo y otras señas anormales, que venía aullando ${ }^{80}$ Estos dos seres están representados en el Códice Xolotl ${ }^{81}$ (figuras 1 y 2).

${ }^{79}$ A partir del Códice Xolotl, Patrick Lesbre, "Nezahualcóyotl", 26, ha notado que no es el "monstruo" el que habla, sino los dos personajes que están en frente de él, los ya mencionados Tlazacuilotzin y Tlacpanhuehuetzin.

${ }^{80}$ Fernando de Alva Ixtlilxóchitl, Sumaria relación, tomo I, 370.

${ }^{81}$ Charles E. Dibble, Códice Xolotl, Primera Serie, núm. 22 (México: Universidad Nacional Autónoma de México, University of Utah, 1951), lám. Ix, c-2, lám. x, c-3. 
Lesbre ${ }^{82}$ ha señalado que ambos fueron convertidos en "monstruos" por los informantes de Alva Ixtlilxóchitl, pero que no deben ser considerados como tales. Indica que el primero -basado en comunicación personal de Alfredo López Austin-correspondería a un "fantasma prehispánico"; y el segundo a un "mal agüero tradicional". El estudioso francés no explica cuáles son sus argumentos para no seńalarlos como "monstruos", y tampoco da una definición de lo monstruoso. ${ }^{83} \mathrm{El}$ hecho de que sean apariciones, y que una de ellas esté relacionada con un agüero, no invalida la naturaleza monstruosa de aquellos seres, cuyas características físicas son más que suficientes para confirmarla.

Como en el caso tolteca, los presagios de destrucción del imperio tepaneca fueron motivados por las transgresiones de Maxtla -acaso también influyeron las faltas de su antecesor Tezozómoc, como fueron la muerte de Ixtlilxóchitl y los inicios de la persecución de Nezahualcóyotl-. A este soberano se le imputaron asesinatos, un deseo desmesurado de poder y un apetito sexual desbordado. Asimismo, se le acusó de soberbia y crueldad. ${ }^{84}$

Por designio divino se presentaron augurios celestes y terrestres que vaticinaron la derrota de los tepanecas. Cito nuevamente la breve pero reveladora información del historiador acolhua respecto a la aparición de tetzahuitl: "hubo muchos prodigios y señales". "En el cielo hubo cometas y eclipse del sol y otras señales; en la tierra se vieron muchos monstruos" ${ }^{85}$ La aparición de un eclipse solar era clara indicación de la potencial destrucción del mundo, pues de prolongarse podían descender las monstruosas diosas tzitzimime a devorar a los mortales. Una vez que el astro salía bien librado de ese crítico trance, el eclipse se convertía en un mal agüero de grandes proporciones. Así como el tlatoani se identificó con el sol, ${ }^{86}$ su eclipse tuvo

${ }^{82}$ Patrick Lesbre, "Nezahualcóyotl”, 26-27.

${ }^{83}$ En las conclusiones de este trabajo delineo una concepción del monstruo desde la cosmovisión nahua.

${ }^{84}$ Patrick Lesbre, "Nezahualcóyotl”, 35; Clementina Battcock, "Aspectos simbólicos", 231.

${ }^{85}$ Fernando de Alva Ixtlilxóchitl, Sumaria relación, tomo I, 370.

${ }^{86}$ Fray Bernardino de Sahagún, Los once discursos, lib. vi, cap. Iv, fol. 12v, 19; cap. v, fols. 16v, p. 31, 18r, 32; fray Diego Durán, Historia de las Indias, tomo I, tratado I, cap. XLI, 375. 
una correspondencia simbólica con la muerte de aquél, tal como nos lo muestran las fuentes: los decesos de Axayacatl, de Tenochtitlan; ${ }^{87}$ Tenancaltzin, de Tenayuca; ${ }^{88}$ Totoquihuatzin, de Tlacopan; Huitzilatzin, de Huitzilopochco; ${ }^{89}$ y el de un señor que tenía por nombre glífico un espejo de obsidiana, ${ }^{90}$ estuvieron relacionados con eclipses de sol. Podemos pensar entonces que dicho fenómeno pudo haber anunciado la muerte de Maxtla.

El deceso del gobernante se asemejaba a la llegada de la noche, por lo que la elección de un nuevo tlatoani representaba el renacimiento de un nuevo sol y el comienzo de una nueva era. ${ }^{91}$ En el mismo sentido, la muerte de aquél simbolizaba el desfallecimiento del astro solar, que podía ser escenificado mediante un eclipse. Esto corresponde a la finalización de un periodo de tiempo dentro de la secuencia temporal más amplia de un imperio; o, de manera drástica, al ocaso del poderío del imperio en turno. Concuerdo con Clementina Battcock ${ }^{22}$ cuando afirma que "La figura de Maxtla se convierte [...] en el ejemplo típico de aquellos malos gobernantes que transgreden y, en consecuencia, 'ocasionan' el fin de una etapa'.

En cuanto al cometa (citlalin popoca), éste fue concebido como un tlatocatetzahuitl, un "augurio real", toda vez que predecía la muerte de señores o de algún noble importante. También señalaba que un noble sería aprisionado o que habría guerra. ${ }^{93}$

Según la versión de Ixtlilxóchitl, ${ }^{44}$ cuando Nezahualcóyotl entró con su ejército a Azcapotzalco, al ver la perdición de la ciudad, los

${ }^{87}$ Anales de Cuaubtitlan, 57; Códice Aubin, manuscrito azteca de la Biblioteca de Berlín, Anales en mexicano y Geroglíficos desde la salida de las tribus de Aztlan hasta la muerte de Cuauhtemoc, versión de 1902 publicada por Antonio Peñafiel (México: Editorial Innovación, 1980), 74.

${ }^{88}$ Fernando de Alva Ixtlilxochitl, Sumaria relación, tomo I, 309. Además de eclipses de sol, con la muerte de este gobernante también hubo eclipses de luna, cometas, y otras "grandes señales y prodigios en el cielo y en la tierra", idem.

${ }^{89}$ Fray Juan de Torquemada, Monarquía Indiana, tomo I, lib. II, cap. LV, 239; cap. LXIX, 270.

${ }^{90}$ CTR, parte III, lám. xxvi, 310 .

${ }^{91}$ Guilhem Olivier, "Les paquets sacrés", 131; "Las tres muertes”, 279.

${ }^{92}$ Battcock, "Aspectos simbólicos", 231.

${ }^{93}$ Fray Bernardino de Sahagún, Augurios y abusiones, 148-149.

${ }^{94}$ Fernando de Alva Ixtlilxóchitl, Sumaria relación, tomo I, 376. 
señores tepanecas fueron tras de Maxtla y con gran vituperio lo llevaron arrastrando frente al acolhua. Con este acto se excusaron de las malas acciones que había cometido su tlatoani. Acto seguido, Nezahualcóyotl mandó hacer un cadalso en medio de la plaza, donde lo sentenció y le dio muerte por su propia mano sacándole el corazón. Luego derramó su sangre por los cuatro rumbos. Posteriormente, mandó que el cuerpo fuera enterrado con todas las honras y solemnidad como tal seńor merecía. ${ }^{95}$

Las señas celestes apuntaron con precisión a la muerte de Maxtla; mientras que la aparición de monstruos significó el estado de desorden que imperaba en el imperio tepaneca. Pero estos seres también se encargaron de anunciar el regreso al estado de orden con el advenimiento de Nezahualcóyotl al poder. En el mismo sentido, Guilhem Olivier ${ }^{96}$ hace la interesante anotación de que "personajes con los miembros inferiores mutilados [...] anuncian el fin de las eras o de los reinos"; y uno de los ejemplos que cita para afirmar lo anterior es precisamente el de un "monstruo de una pierna [que] profetiza la caída del tirano tepaneca Maxtla". Aquí Olivier se refiere al "monstruo a gatas, con un pie y dos manos como de persona" citado arriba.

\section{LA CAÍdA DE TENOCHTITLAN Y LLEGADA DE GENTE EXTRANJERA}

El caso de la destrucción de Tenochtitlan sigue el mismo modelo que en los dos ejemplos anteriores: transgresiones del gobernante; aparición de fenómenos celestes y de monstruos que anuncian la destrucción del orden imperante y la imposición de uno nuevo. Pero al mismo tiempo es diferente por ser los nuevos detentadores

\footnotetext{
${ }^{95}$ Sobre las versiones de la muerte de Maxtla, véase Clementina Battcock, "Aspectos simbólicos".

${ }^{96}$ Guilhem Olivier, "Homosexualidad y prostitución entre los nahuas y otros pueblos del Posclásico", en Historia de la vida cotidiana en México, I Mesoamérica y los ámbitos indigenas de la Nueva España, dir. Pilar Gonzalbo Aizpuru, coord. Pablo Escalante Gonzalbo, 415, nota 8 (México: Fondo de Cultura Económica, El Colegio de México, 2004).

${ }^{97}$ Fernando de Alva Ixtlilxóchitl, Sumaria relación, tomo I, 370.
} 
del poder de una naturaleza totalmente distinta. Igualmente, algunas señas celestes fueron sui generis, lo que denota un contexto futuro diametralmente diferente.

Michel Graulich ${ }^{98}$ señala que aunque la inmensa mayoría de las fuentes concernientes a los mexicas son posteriores a 1530, no debe de refutarse en bloque la autenticidad de todos los presagios de la conquista de Tenochtitlan. Entre el descubrimiento de América y la conquista de México hubo una veintena de años en los que debieron penetrar ecos de cataclismos hasta el México central, y "ahí crear sentimientos de angustia que hicieron interpretar los fenómenos naturales y visiones de espanto como anuncios de catástrofes".

No estoy totalmente de acuerdo con el investigador. Si atendemos a lo que dicen las fuentes de tradición nahua, la concepción de los eventos naturales como anuncios de hechos aciagos no fue un producto del Posclásico Tardío, representado principalmente por los mexicas, sino que tuvo su antigüedad mínimo desde las postrimerías del Posclásico Temprano, con la caída del imperio tolteca, siglos antes del derrumbe de Tenochtitlan. Y seguramente dicha concepción fue mucho más antigua. Otro aspecto es que el material mítico referente a los Soles debió haber sido un aspecto de la cosmovisión mesoamericana de profundidad histórica, donde los fenómenos naturales conformaron un aspecto medular de dichas edades al ser los causantes de su destrucción.

Por otro lado, no debemos perder de vista que en la reconstrucción a posteriori de los hechos, las antiguas poblaciones nahuas recurrieron a una concepción mítica de la historia, en la que lo maravilloso cobró un importante papel, tanto en la conducción de los acontecimientos como en su interpretación. Entonces, más allá de considerar si tal presagio realmente ocurrió, tenemos que reparar en la historiografía de la Conquista de tradición nahua, es decir, en la manera como fue estructurada la narración histórica de dicho evento por los nahuas. ${ }^{99}$

${ }^{98}$ Michel Graulich, "Los presagios de la caída del imperio azteca”, Cuicuilco (31/32) (julio/diciembre 1992), 93.

${ }^{99}$ Miguel Pastrana, Historias de la Conquista, 7-8. 
Los informantes nahuas de Sahagún elaboraron una lista de ocho augurios que predijeron la Conquista, entre los cuales se encuentran varios acontecimientos naturales y la aparición de monstruos. ${ }^{100}$ Sin embargo, en otras fuentes encontramos hechos diferentes -señas de orden natural, guerras, otro tipo de presencias monstruosas- que forman parte del conjunto de señales que pronosticaron la caída de Tenochtitlan. Voy a centrar mi atención en los presagios que tienen que ver con fenómenos naturales y con presencias monstruosas, razón por la que no abordo todos los augurios de la obra sahaguntina.

Antes de la aparición del primer tetzahuitl registrado por Sahagún y recopilado por otras fuentes: la gran pirámide de fuego, los mexicas celebraron en el año ome acatl ("dos caña"), 1507, la construcción del templo del Fuego Nuevo en la cima del Huixachtépetl, de acuerdo con los códices Telleriano-Remensis ${ }^{101}$ y Vaticano Latino 3738. ${ }^{102}$ Para Torquemada, ${ }^{103}$ se llevó a cabo la celebración del Fuego Nuevo en la cual se sacrificaron cautivos de Tecuhtépec. Durante la ceremonia hubo un eclipse de sol, que fue interpretado por Nezahualpilli como un pronóstico del cambio de gobierno y la instauración de uno nuevo por gente venida de fuera. ${ }^{104}$

Por su parte, el texto Costumbres, fiestas y enterramientos... ${ }^{105}$ señala que en el año en que entró Cortés a México se intentó encender el fuego nuevo, pero no se pudo realizar sino hasta el tercer día. Esto

${ }^{100}$ Fray Bernardino de Sahagún, Historia general, tomo III, lib. XII, cap. I, 1,1611,162; también Diego Muñoz Camargo, Historia de Tlaxcala, 173-177.

${ }^{101} C T R$, parte III, lám. xxv, 308.

${ }^{102}$ CVL 3738, lám. cxxix, 278.

${ }^{103}$ Fray Juan de Torquemada, Monarquía Indiana, tomo I, lib. II, cap. LXxvI, 289; cap. LXXVII, 291.

${ }^{104}$ Es muy interesante el comentario que hace Torquemada sobre los dos eventos anteriores -Fuego Nuevo y eclipse-, pues, sugiere que si el atado de años hubiera sucedido cuando los espańoles entraron a la ciudad de Tenochtitlan, y debido a la frecuencia de eclipses de sol en el discurso indígena, la interpretación nahua sobre el fin de un imperio relacionado con estos eventos se hubiera visto corroborada. De esta manera, el poder de Motecuhzoma se habría oscurecido frente a los españoles tal como se oscurece el sol con un eclipse, fray Juan de Torquemada, Monarquía Indiana, tomo I, lib. II, cap. LXXVI, 289.

105 "Costumbres, fiestas y enterramientos y diversas formas de proceder de los indios de Nueva España”, publicado por Federico Gómez de Orozco, Tlalocan 2(1) (1945): fol. $387 \mathrm{v}, 62-63$. 
Figura. 3. Augurio de la pirámide de fuego

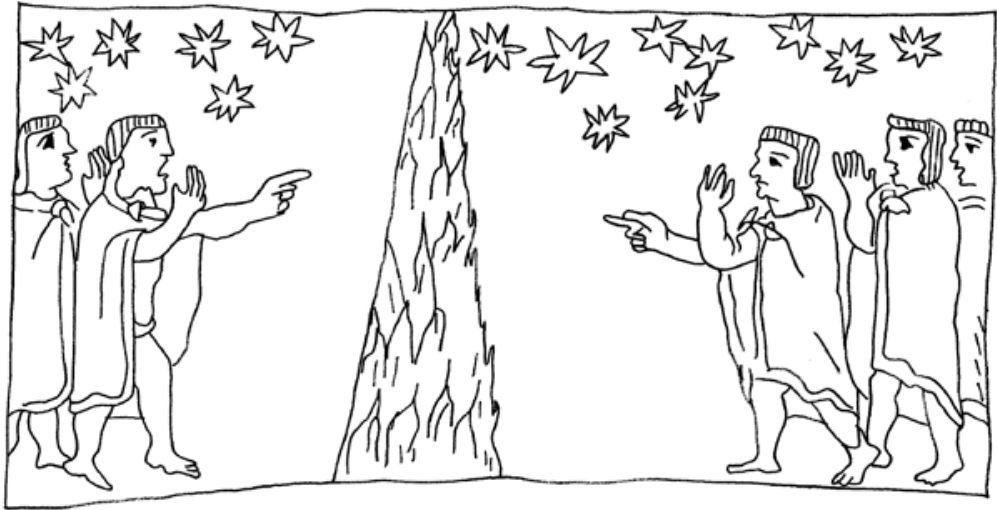

Fuente: Fray Bernardino de Sahagún, Códice Florentino, edición facsimilar. 3 tomos. México: Archivo General de la Nación, 1979, lib. xII, cap. I, fol. 3r. Dibujo de Jaime Echeverría.

fue concebido como vaticinio de perdición y calamidad. También se comenta que en el mismo ańo, todas las mañanas cuando salía el sol, el astro era cubierto por humo que exhalaba de la tierra, el cual se deshacía posteriormente en las nubes. Este acontecimiento fue tomado por tetzahuitl.

Un fenómeno totalmente inusual fue el que ocurrió diez años antes de la llegada de los españoles, que consistió en una pirámide de fuego de base ancha, que se originaba en el suelo después de media noche por el oriente, y se iba angostando al llegar al cielo hacia el occidente. Ésta salía con tanto resplandor que parecía de día; y cuando llegaba la mañana se perdía. Durante un año apareció cada noche y comenzó en el año 12 calli (“casa”) (figura 3). Éste fue llamado mixpanitlo mixpantli y tlemiahuatl. ${ }^{106} 107$

Tal señal les recordaba que ya se acercaban los tiempos en que Quetzalcóatl regresaría, y a quienes más les consternaba esto era a

${ }^{106} \mathrm{CF}$, lib. viII, cap. I, 3-4; lib. XII, cap. I, 1-2; fray Bernardino de Sahagún, Historia general, tomo III, lib. XII, cap. I, 1,161; Diego Muñoz Camargo, Historia de Tlaxcala, 173-174; fray Juan de Torquemada, Monarquía Indiana, tomo I, lib. II, cap. Xc, 320.

${ }^{107}$ Miguel Pastrana trató ampliamente este tetzahuitl en su libro Historias de la Conquista, 32-33, 45-48. 
Nezahualpilli y Motecuhzoma, pues en ellos se habría de ejecutar el cambio de orden político. Y a partir de este mal agüero, "cada día se veían nuevas señales y grandes prodigios y portentos, que anunciaban la ruina y total destrucción de toda esta tierra y mudanza de todo el imperio". ${ }^{108}$

Fray Diego Durán ${ }^{109}$ describe este augurio en los mismos términos, pero señala un cometa en lugar de la pirámide de fuego. ${ }^{110} \mathrm{Tal}$ signo fue interpretado por Nezahualpilli como pronóstico de hechos aciagos: grandes calamidades, muertes innumerables, pérdida de señoríos, y esto por la voluntad del "Señor de las alturas, del día y de la noche y del ayre". Otros astrólogos y adivinos le predijeron a Motecuhzoma "pestilencias, muertes, hambres, guerras y mortandades; otros muertes de príncipes y grandes señores". Aunque me inclino a pensar que el augurio del que habla Durán es la pirámide de fuego, debe considerarse que las anteriores interpretaciones corresponden tanto a uno como a otro, pues algunas de ellas como mortandades, pestilencias, guerras y muerte de principales fueron propias del cometa, como ya se ha mencionado.

Justamente en el mismo año que apareció la pirámide de fuego, los ejércitos de la triple alianza fueron a combatir a la provincia rebelde de Amatlan. A mitad del camino les sobrevino una gran tempestad de nieve junto con fuertes vientos; y como se encontraban entre las montañas y los bosques, a causa del frío murieron muchos, mientras que otros perecieron por los golpes de piedras que se derrumbaron sobre ellos. Al llegar los sobrevivientes a Amatlan, como eran un número insuficiente para la guerra, la mayoría murió. A su regreso a Tenochtitlan, el escaso número de cautivos no satisfizo el esperado. ${ }^{111}$

${ }^{108}$ Fernando de Alva Ixtlilxóchitl, Compendio histórico del reino de Texcoco, en Obras Históricas, tomo I, cap. LXxII ed. Edmundo O'Gorman, 181-182 (Toluca: Instituto Mexiquense de Cultura, Universidad Nacional Autónoma de México, Instituto de Investigaciones Históricas, 1997b).

${ }^{109}$ Durán, Historia de las Indias, tomo I, tratado I, cap. LXIII, 535, 537.

110 "Podría ser que el dominico se confundiera ante la descripción de la 'bandera de nubes' y tratara de identificar el fenómeno como algo conocido para él, con lo que único que se le parecía, un cometa”, Miguel Pastrana, Historias de la Conquista, 46.

${ }^{111}$ Fray Juan de Torquemada, Monarquía Indiana, tomo I, lib. II, cap. LxxvI, 290; Fernando de Alva Ixtlilxóchitl, Historia de la nación chichimeca, tomo II, cap. LXXIII, 184. 
Existen otras versiones sobre este primer augurio. Dos fuentes dicen que fue una claridad muy grande y resplandeciente que duró más de 40 días, a la cual llamaron mexpanitli, que estaba en el oriente y que pensaban que era Quetzalcóatl. ${ }^{12}$ Mientras que Alvarado Tezozómoc ${ }^{113}$ señala que se vio del oriente un humo espeso y tan blanco que relumbraba, y que parecía que venía andando como un gran gigante blanco.

Según fray Andrés de Olmos, mixpanitl (mexpanitli) significa "gran nube", 114 literalmente es "bandera de nube". ${ }^{115}$ Dicho vocablo formó parte de una expresión registrada por el franciscano ${ }^{116}$ que reproduzco a continuación: Auh tepan moquetza in mixpanitl, in tlemiahuatl, itztic cecec quiztoc, icnoyutl quiztoc, "sobre la gente se levanta la bandera de nube, la espiga de fuego, arroja frío, helada, arroja miseria". ${ }^{117} \mathrm{El}$ significado que Olmos le dio a esta expresión es: "Tener alguno pobreza o hambre". Por medio del verbo quetza. nino, erguirse, levantarse, se expresa el movimiento del mixpanitlen la metáfora, tal como fue percibido en vísperas de la Conquista: como una columna de fuego que se levantaba del suelo hacia el cielo; mientras que la figura retórica de su levantamiento sobre la gente es, a mi parecer, lo que indica el mal venidero. Con base en la expresión asentada por el franciscano, Pastrana ${ }^{118}$ infiere que dicho portento "presagiaba la llegada de heladas, lo que traería como consecuencia malas cosechas con su grave secuela de hambre y miseria para los hombres". En concordancia con la interpretación del

${ }^{112}$ CTR, parte III, lám. xxv, 308; CVL 3738, lám. cxxix, 278.

${ }^{113}$ Hernando Alvarado Tezozómoc, Crónica Mexicana, cap. c, notas de Manuel Orozco y Berra (México: Editorial Leyenda, 1944), 484.

${ }^{114}$ Citado por Rémi Siméon, Diccionario de la lengua náhuatl o mexicana, trad. Josefina Oliva de Coll (México: Siglo XXI, 2002), 280.

${ }^{115}$ José Corona Núnez identifica al mixpanitli como una aurora boreal, CTR, parte III, lám. xxv, 308; CVL 3738, lám. Cxxix, 278.

${ }^{116}$ Fray Andrés de Olmos, Arte de la lengua mexicana, Facsímiles de Lingüística y Filología Nahuas 9, iII parte, cap. viII, ed. Ascensión Hernández de León-Portilla y Miguel León-Portilla, 192 (México: Universidad Nacional Autónoma de México, Instituto de Investigaciones Históricas, 2002).

${ }^{117}$ Traducción propia.

${ }^{118}$ Miguel Pastrana, Historias de la Conquista, 33. 
estudioso, algunas de las tribulaciones vaticinadas por este tetzahuitl fueron hambres y mortandades, como se señaló arriba.

A partir de la comparación del mixpanitl con la xiuhcoatly el mamalhuaztli se puede decir algo sobre la concepción de la desgracia. Estos dos eran objetos vinculados con el fuego: uno cometa y otro constelación -identificada con Astillejos-, ${ }^{119}$ respectivamente. Además, el mamalhuaztli era el nombre que recibían los palos para hacer el fuego. ${ }^{120}$ Ambos formaron parte de una metáfora que significaba desgracia. Asienta el Códice Florentino que Huitzilopochtli "arroja sobre la gente la xiuhcoatl, el mamalhuaztli, esto es, la guerra" ${ }^{121}$ Para una ampliación del significado de la metáfora contamos con una frase en náhuatl registrada igualmente por Olmos: ${ }^{122}$ Xiuhcoatl, mamalhuaztli tepan quimotlaxilia, tepan quimochiuilia yn Dios, que traduce como "Da Dios hambre o enfermedad", literalmente: "Dios le arroja a la gente el xiuhcoatl, el mamalhuaztli; los crea sobre la gente". ${ }^{123}$ Su relación con el fuego así como su sentido metafórico de hambre o enfermedad pudo haberlos emparentado en significado con el mixpanitlo tlemiahuatl.

La relación que existe entre el sufrimiento y el fuego se refuerza en el vocablo cococ, el cual tiene por acepciones, de acuerdo con Molina, "quemar alguna cosa como pimienta o axi" y "tribulacion". ${ }^{124} 125$ De esta manera, el hambre, la enfermedad, la guerra, y la desdicha, en general, eran expresadas por medio de objetos que

${ }^{119}$ Fray Alonso de Molina, Vocabulario en lengua castellana y mexicana y mexicana y castellana, sección náhuatl-español, fol. 52r, ed. Miguel León-Portilla (México: Editorial Porrúa, 2004); fray Bernardino de Sahagún, Historia general, tomo II, lib. viI, cap. III, 699.

${ }^{120}$ Debido a la semejanza de forma que veían entre los palos hacedores de fuego y Astillejos, esta constelación recibió el nombre mamalhuaztli, fray Bernardino de Sahagún, Historia general, tomo II, lib. vII, cap. III, 699.

${ }^{121} C F$, lib. I, cap. I, 1.

${ }^{122}$ Fray Andrés de Olmos, Arte de la lengua mexicana, III parte, cap. VIII, 190, también 192.

${ }^{123}$ Traducción propia.

${ }^{124}$ Fray Alonso de Molina, Vocabulario, sección español-náhuatl, fols. 100v, 115r.

${ }^{125}$ Cuando Tezcatlipoca andaba en la Tierra introducía cococ teopouhqui, CF, lib. I, cap. III, 2, esto es, "angustia, aflicción y trabajo" en palabras de fray Alonso de Molina, Vocabulario, sección náhuatl-español, fol. 101r. 
poseían una naturaleza ardiente. La desgracia se experimentaba como si ésta quemara.

El fenómeno mixpanitl fue totalmente inusual y nunca antes visto, así como su duración, lo cual debió haber constituido los criterios que ayudaron a definir lo que presagiaba. La extrañeza del mismo reflejaba su gravedad, por lo que podía pronosticar una serie extensa de calamidades, pero al mismo tiempo dejaba constancia del desconocimiento y la imprecisión que se tenía de dicho augurio. También se podría pensar que al ser el primer tetzahuitl de la conquista, éste delineó todas las calamidades que debían ocurrir antes de que llegaran los espańoles e impusieran su nuevo orden de las cosas.

Ante la aparición de este mal augurio se produjo un miedo muy intenso manifestado en gritos desgarradores, llantos y alaridos producidos con las palmas en las bocas, gesto que era la típica manifestación corporal masculina del miedo. ${ }^{126}$ Estas expresiones estuvieron acompañadas de autosacrificios e inmolaciones de personas, como lo solían hacer cuando estaban frente a una gran tribulación, como un eclipse solar. Esto lo efectuaron con el fin de conocer el significado divino de tal agüero. ${ }^{127}$ A partir del despliegue de estas prácticas culturales igualmente se infiere la gravedad del augurio.

Al examinar brevemente los presagios del fin de Tollan, Guilhem Olivier ${ }^{128}$ establece una interesante comparación entre el augurio del incendio del cerro Zacatépetl en tiempos toltecas ${ }^{129}$ y el mixpanitl de los mexicas. La pirámide de fuego se asemeja en su forma al cerro encendido cuyas flamas se elevaban alto. Asimismo, las expre-

${ }^{126}$ Fray Bernardino de Sahagún, Historia general, tomo II, lib. vII, cap. I, 693; Muñoz Camargo, Historia de Tlaxcala, 174; fray Gerónimo de Mendieta, Historia eclesiástica indiana, tomo I, lib. II, cap. XVI, 215; fray Juan de Torquemada Monarquía Indiana, tomo I, lib. II, cap. xc, 320. Remito al lector al artículo de Jaime Echeverría García y Miriam López Hernández, "La expresión corporal del miedo entre los antiguos nahuas", Anales de Antropología 47(1) (junio 2013): 148-152, para conocer más sobre dicho gesto.

${ }^{127}$ Diego Muñoz Camargo, Historia de Tlaxcala, 173-174; fray Bernardino de Sahagún, Augurios y abusiones, 145; fray Juan de Torquemada, Monarquia Indiana, tomo I, lib. II, cap. xc, 320.

${ }^{128}$ Guilhem Olivier, "Homosexualidad y prostitución”, 247.

${ }^{129}$ CF, lib. III, cap. x, 29. 
siones de miedo que mostró la población frente a ambos presagios son prácticamente idénticas: en Tollan "había golpes de labios, había gritos cuando se golpeaban los labios" (in netenvitecoia, in netenpapaviloia); ${ }^{130}$ mientras que en Tenochtitlan "había gritos, había golpes de labios" (tlacaoacaia, netenvitecoia). ${ }^{131}$ Este tipo de comparaciones demuestra una vez más la utilización de imágenes similares en la construcción de los acontecimientos de fin de periodo, que a su vez remiten a un modelo mítico-histórico que delineó el discurso histórico nahua. ${ }^{132}$

Regreso con los gestos que demostró la población ante la presencia del mixpantli. Así como ocurrió con este evento, durante el eclipse solar el llanto y los gritos no sólo fueron concebidos como expresiones de miedo, sino que eran propiciados para ayudar al sol en su lucha contra la luna, ${ }^{133}$ pues, la producción de ruido era necesaria para generar un ambiente de vida que se oponía al proceso de muerte que padecía el astro solar. ${ }^{134}$ De igual manera, la sangre era un elemento que restituía las fuerzas menguadas del sol. Cuando había eclipse, la sangre que se extraía del cuerpo por autosacrificio era arrojada hacia el astro con los dedos. ${ }^{135}$ Esta medida ritual fue reproducida en el augurio de la pirámide de fuego con el objetivo de que el fenómeno desapareciera o para contrarrestar los males que pudiera vaticinar, que fueron varios.

${ }^{130}$ Idem.

${ }^{131} C F$, lib. xII, cap. I, 2.

${ }^{132}$ Guilhem Olivier, "Homosexualidad y prostitución”, 248.

${ }^{133}$ Diego Muñoz Camargo, Historia de Tlaxcala, 149. Para un ejemplo tzotzil contemporáneo véase Calixta Guiteras Holmes, Los peligros del alma. Visión del mundo de un tzotzil, trad. Carlo Antonio Castro (México: Fondo de Cultura Económica, 1996), 133.

${ }^{134}$ Llego a esta interpretación a partir del cruce del dato etnográfico y la información histórica, Jaime Echeverría García, “El Sol es comido’: representaciones, prácticas y simbolismos del eclipse solar entre los antiguos nahuas y otros grupos mesoamericanos", Revista Española de Antropología Americana 44(2) (2014), 378-379.

${ }^{135}$ Fray Toribio de Benavente, Memoriales cap. Ix, 183; fray Bartolomé de Las Casas, Apologética historia sumaria. Cuanto a las cualidades disposición, descripción cielo y suelo destas tierras, y condiciones naturales policías, repúblicas, manera de vivir e costumbres de las gentes destas indias occidentales y meridionales cuyo imperio soberano pertenece a los reyes de Castilla, tomo II, lib. III, cap. CLXxIV, ed. Edmundo O'Gorman, 201-202 (México: Universidad Nacional Autónoma de México, Instituto de Investigaciones Históricas, 1967. 
Figura 4. Cometa

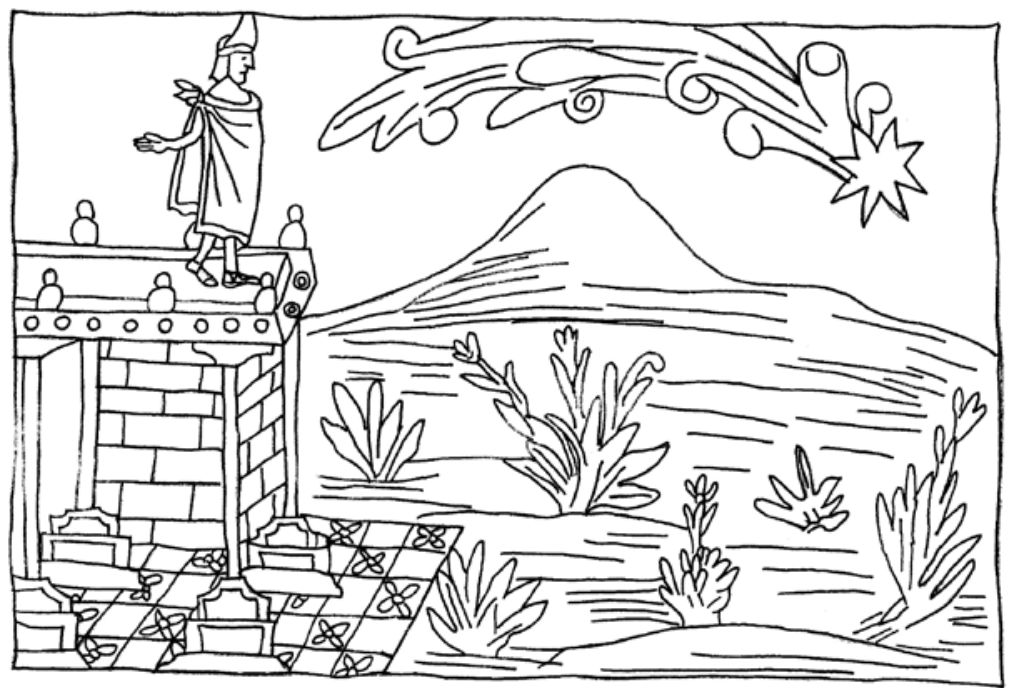

Fuente: Fray Diego Durán, Historia de las Indias, tomo I, lám. 48. Dibujo de Jaime Echeverría.

El cuarto tetzahuitl corresponde a la aparición de un cometa a plena luz del día (figura 4). Éste tenía tres cabezas que parecían como tres estrellas juntas encendidas, que corrían a la par de occidente a oriente. Tenía unas largas colas y echaba centellas. Desde que la gente lo vio comenzaron a dar gritos y alaridos, y "sonó grandísimo ruido en toda la comarca". ${ }^{136}$ De nuevo se observa la producción de ruido en extremo, tanto como expresión de miedo como posiblemente para aminorar el vaticinio funesto del cometa. Fue tan intenso el temor que provocó que parecía el fin del mundo, declaró Durán. ${ }^{137}$ Este augurio parece describir a una citlalin tlamina, "estrella tira flecha”.

La interpretación que dio Nezahualpilli de este signo consistió en que vendrían gentes blancas y barbadas de tierras extrańas a se-

${ }^{136}$ Fray Bernardino de Sahagún, Historia general, tomo III, lib. XII, cap. I, 1,1611,162; Diego Muñoz Camargo, Historia de Tlaxcala, 175-176; fray Juan de Torquemada, Monarquía Indiana, tomo I, lib. II, cap. xc, 321.

${ }^{137}$ Fray Diego Durán, Historia de las Indias, tomo I, tratado I, cap. LXIII, 538. 
ñorearse de la tierra. ${ }^{138}$ Como llegarían de oriente, referirían a Quetzalcóatl, razón por la que serían invencibles, además de que traerían consigo armas nunca antes vistas. ${ }^{139}$ Esta predicción se vio reforzada al desembarcar Cortés en las costas de Veracruz en el año ce acatl ("uno caña”) (1519). ${ }^{140}$ Precisamente Quetzalcóatl nació y abandonó Tollan en un ańo uno cańa, y fue a morir a Tlapallan en el oriente. ${ }^{141}$

Cada fenómeno natural tenía un significado específico, pero al estar enmarcado dentro de un contexto determinado y relacionado con otra serie de eventos, se le podía dotar de un significado más profundo y tener un mayor impacto. Y si dicho fenómeno se mostraba de forma inusitada su predicción debía ser de mayor envergadura. Aunque el cometa presagiaba desgracias terrenales específicas, la interpretación ofrecida por el tlatoani acolhua de este augurio fue más allá, era de orden cósmico, es decir, vaticinaba con seguridad un cambio de era.

El quinto tetzahuitl refiere que el agua de la laguna de Tenochtitlan se alteró sin haber viento alguno. Hervía y espumaba tanto que se alzaron las olas a gran altura y arrasaron e inundaron más de la mitad de las casas de la ciudad. La gente cobró mucho espanto ante insólito acontecimiento. Algunos años después de este incidente hubo una gran hambruna en toda la tierra, excepto en el Totonacapan. ${ }^{142}$

Con respecto al octavo tetzahuitl, éste correspondió a la aparición de monstruos. ${ }^{143}$ Éstos consistieron en dos hombres unidos por el

${ }^{138}$ Uno de los augurios de la llegada de los españoles entre los tarascos fue la presencia de "dos grandes cometas en el cielo", lo que les hizo pensar que "sus dioses habían de conquistar o destruir algún pueblo, y que ellos habían de ir a destruille”, Jerónimo de Alcalá, Relación de Michoacán, fol. 36, 233.

${ }^{139}$ Fray Juan de Torquemada, Monarquía Indiana, tomo I, lib. II, cap. LXIV, 260.

${ }^{140}$ CVL 3738, lám. CxxxiII, 286.

${ }^{141}$ Leyenda de los Soles, 185; Fernando de Alva Ixtlilxochitl, Sumaria relación, tomo I, 275.

${ }^{142}$ Fray Bernardino de Sahagún, Historia general, tomo III, lib. XII, cap. I, 1,162; Diego Muñoz Camargo, Historia de Tlaxcala, 176; fray Juan de Torquemada, Monarquía Indiana, tomo I, lib. II, cap. Xc, 321.

${ }^{143}$ Fray Bernardino de Sahagún, Historia general, tomo III, lib. XII, cap. I, 1,162; Diego Muñoz Camargo, Historia de Tlaxcala, 177. 
Figura 5. Aparición de un hombre de dos cabezas
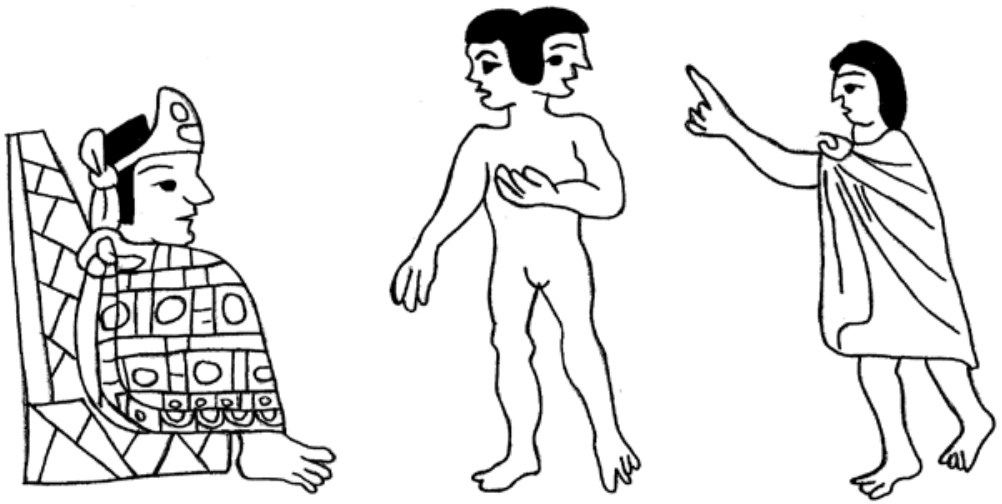

Fuente: Fray Bernardino de Sahagún, Códice Florentino, lib. viII, cap. I, fol. 13r. Dibujo de Jaime Echeverría.

cuerpo que los nahuas llamaban tlacanetzolli, presumiblemente un siamés. Otra visión fue la de un hombre de dos cabezas (figura 5). ${ }^{144}$

Las presencias monstruosas en vísperas de la caída de Tenochtitlan no se limitaron a las anteriores. Primero, el indio que le informó a Motecuhzoma Xocoyotzin sobre la llegada de un barco espańol -cuya manera de explicarlo fue diciendo que era un cerro redondo que se desplazaba en el mar- tenía unos rasgos físicos muy particulares: le faltaban las orejas y los dedos pulgares de manos y pies. ${ }^{145}$

$\mathrm{Al}$ inquirir Motecuhzoma sobre la gente que había llegado a las costas veracruzanas, le fue enseńada una pintura en Malinalco en la que estaban pintados "unos hombres con un ojo en la frente, como cíclopes". Los malinalcas le comentaron al tlatoani que sus antepasados dejaron dicho que aquellos que vendrían poseerían la tierra, y algunos no tendrían más que un pie. Asimismo, la gente de Cuauhnahuac le mostró otra pintura con la representación de criaturas antropozoomorfas con cuerpo de hombre y de pez. Otros también

${ }^{144}$ Fray Bernardino de Sahagún, Historia general, tomo III, lib. XII, cap. I, 1,162; Diego Muñoz Camargo, Historia de Tlaxcala, 177; fray Juan de Torquemada, Monarquía Indiana, tomo I, lib. II, cap. xc, 322.

${ }^{145}$ Fray Diego Durán, Historia de las Indias, tomo I, tratado I, cap. LXIX, 575. 
le enseñaron un dibujo con seres que en vez de tener la mitad del cuerpo con forma de pez, era de serpiente. ${ }^{146}$

Alvarado Tezozómoc ${ }^{147}$ proporciona dos nombres de la gente que vendría a habitar la tierra. Vaticinaron los antepasados "que los que habían de venir á reinar y poblar estas tierras, que habían de ser llamados Tezocuilycxique, y por otro nombre Centeycxique, que son aquellos que están en los desiertos de Arabia, que el alto sol enciende, que tienen un pié solo, de una pata muy grande con que se hacen sombra y las orejas les sirven de frezadas, que tienen la cabeza en el pecho".

Un hombre sabio de Xochimilco también fue consultado para el mismo propósito. Éste le mostró al tlatoani tenochca una pintura que retrataba "unas gentes que serán llamadas Coayxeequee, caras de culebras y caras de pescado grandes, y piés de gusanos, gentes de un pie". También "vendrán luego otros de un pie, y han de venir otras gentes que no tienen cabezas, sino en los pechos". ${ }^{148}$

Georges Baudot ${ }^{149}$ comenta que los monstruos que auguraron la llegada de los españoles posiblemente fueron una elaboración a posteriori, pues los textos que los mencionan fueron redactados mucho después de la conquista (1598), y no se han encontrado fuentes prehispánicas que hablen de su existencia. Por su parte, Michel Graulich ${ }^{150}$ comenta que

el bestiario fantástico -cíclopes, sirenas, hombres con pie-sombrilla u orejas-frazadas, etcétera- recuerda más lo maravilloso occidental que los códices precolombinos. Plinio lo describe, San Agustín lo menciona en su Ciudad de Dios (16, 8), la Edad Media lo heredó y lo encontramos en los mapas de África de esa época. Tan es así que el propio Alvarado Tezozómoc ubica a los hombres con pie-sombrilla en jlos “desiertos de Arabia!".

${ }^{146}$ Ibid., cap. LXX, 584.

${ }^{147}$ Hernando Alvarado Tezozómoc, Crónica mexicana, precedida del Códice Ramirez manuscrito del siglo Xvi intitulado: Relación del origen de los Indios que habitan esta Nueva España según sus historias, Biblioteca Porrúa de Historia 61, cap. CVIII, ed. Manuel Orozco y Berra, 692 (México: Editorial Porrúa, 1987).

${ }^{148}$ Ibid., cap. cIX, 695.

${ }^{149}$ Georges Baudot, "Alteridad y monstruosidad", 54-55.

${ }^{150}$ Michel Graulich, Moctezuma, 302. 
Figura 6. Sciápodo

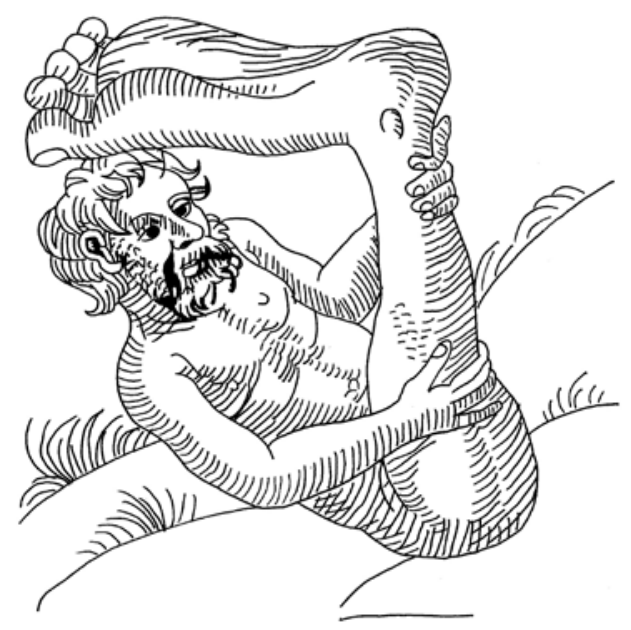

Fuente: Conrad Lycosthenes, Prodigiorum ac ostentorum chronicon. Dibujo de Jaime Echeverría.

En un intento por conciliar las concepciones indígena y española, Rocío Cortés ${ }^{151}$ plantea que aunque se presenta en la Crónica mexicana una "apropiación de elementos mitológicos de tradición europea" en la forma de los presagios, refiriéndose justamente a los seres que vendrían a poblar la tierra, la mecánica de los mismos sigue perteneciendo a la antigua tradición indígena.

Hernando Alvarado Tezozómoc señaló que vendrían seres de un pie, que de grande que era se hacían sombra con él, y que tenían la cabeza en el pecho. Efectivamente, esta imagen monstruosa es muy antigua, y en realidad corresponde a dos seres diferentes, como precisa páginas después el historiador tenochca: los que poseen un solo pie y los que tienen la cabeza en el pecho. Ya los griegos y romanos los habían referido como seres que habitaban en África y Asia, como fue el caso de Plinio el viejo (I d. C.) en su Historia natural. Posteriormente, estos mismos seres, nombrados sciápodos y blemis

${ }^{151}$ Rocío Cortés, "Motecuzoma/Huemac”, 36-38. 
Figura 7. Blemmy

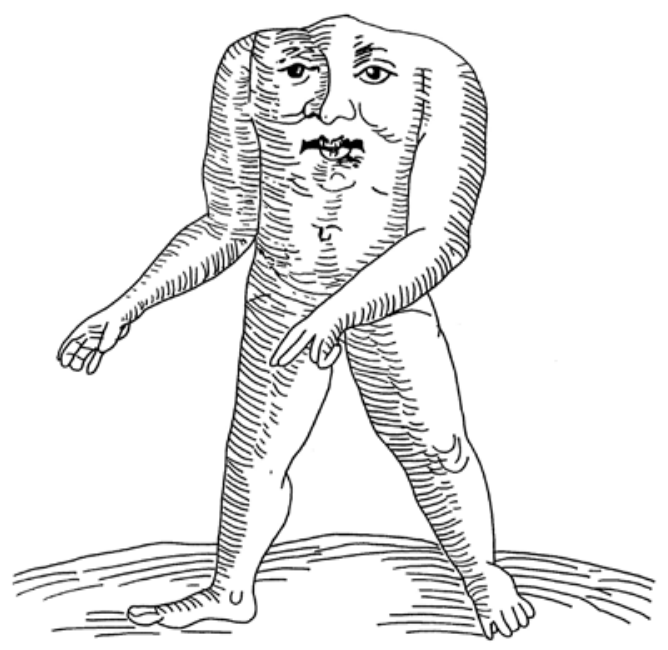

Fuente: Conrad Lycosthenes, Prodigiorum ac ostentorum chronicon. Dibujo de Jaime Echeverría.

(figuras 6-7), respectivamente, fueron heredados a la Edad Media y el Renacimiento, como se observa en la obra Prodigiorum ac ostentorum chronicon de Conrad Lycosthenes (1557). ${ }^{152}$

Los relatos de la Conquista de tradición indígena fueron, ciertamente, escritos tiempo después de los acontecimientos; y su reconstrucción estuvo expuesta a variadas manipulaciones e influencias provenientes de tradiciones culturales diferentes. Alvarado Tezozómoc importó figuras míticas de la antigüedad grecolatina a la historia mexica; pero, como señala Cortés, la mecánica del presagio siguió conservando la estructura de pensamiento indígena. En varias ocasiones hemos apuntado la inclusión de figuras monstruosas en los relatos de vaticinios de destrucción de imperios, tal como sucedió con Tollan y con el imperio tepaneca. Y ocurre exactamente lo mismo con los presagios de la caída de Tenochtitlan. Esta recurren-

${ }^{152}$ Véase Lucian Boia, Entre el ángel y la bestia, trad. Andrea Morales Vidal (Barcelona: Editorial Andrés Bello, 1997), 78. 
cia apunta sin lugar a dudas a un modelo mítico-histórico en el que se apoyaron los nahuas para construir los acontecimientos de fin de periodo. En dicho modelo, los monstruos -como se ha sostenido anteriormente- tienen la función de anunciar, por un lado, la caída de un imperio o de una ciudad debido a la ausencia de orden -básicamente originada por las transgresiones del gobernante-; y por otro lado, la imposición de un nuevo poder.

La mera presencia de la figura monstruosa como presagio de la ruina de Mexico-Tenochtitlan sería demostrativa de lo anterior, pero podemos aportar algunos datos que lo refuercen. Baudot afirmó que no se han encontrado fuentes prehispánicas que hablen de la existencia de los monstruos asentados por Alvarado Tezozómoc. Si al decir el estudioso "fuentes prehispánicas" se refiere a la tradición indígena, debemos señalar, en su contra, que por lo menos uno de los seres monstruosos nombrado por el historiador tenochca sí correspondió a dicha tradición. Tezozómoc mencionó que los habitantes que vendrían a señorearse de la tierra serían llamados tezocuilycxique. La escritura de la palabra puede prestarse un poco a confusión, pero el Códice Vaticano Latino $3738^{153}$ y Alva Ixtlilxóchit ${ }^{154}$ nos proporcionan sustantivos escritos de muy semejante manera: tzocuillicxeque y tzocuilhicxime. Éstos se identifican con los gigantes, también llamados quinametin, quienes vivieron en el Sol Tlalchitonatiuh (Sol de Tierra) (figura 8). ${ }^{155}$ Con seguridad, los personajes nombrados por Alvarado Tezozómoc son los mismos gigantes.

Alfredo López Austin ${ }^{156}$ afirma que "Los términos tzocuilicxeque y tzocuilicxime se refieren a las deformadas extremidades inferiores de los gigantes, pues ambos nombres significan 'los que tienen patas de jilgueros"'. La traducción etimológica de los vocablos mantiene

${ }^{153}$ CVL 3738, lám. v, 19.

${ }^{154}$ Fernando de Alva Ixtlilxóchitl, Historia de la nación chichimeca, tomo II, 7.

155 "Histoyre du Mechique", cap. vi, 145; Anales de Cuauhtitlan, 5; Fernando de Alva Ixtlilxóchitl, Sumaria relación, tomo I, 264.

${ }^{156}$ Alfredo López Austin, Cuerpo humano e ideología. Las concepciones de los antiguos nahuas, tomo I (México: Universidad Nacional Autónoma de México, Instituto de Investigaciones Antropológicas, 1996), 266. 
FIGURA 8. Un gigante aparece recostado debajo de la representación de la destrucción del Sol de Agua. Se indica su nombre en náhuatl pluralizado: tzocuillicxeque

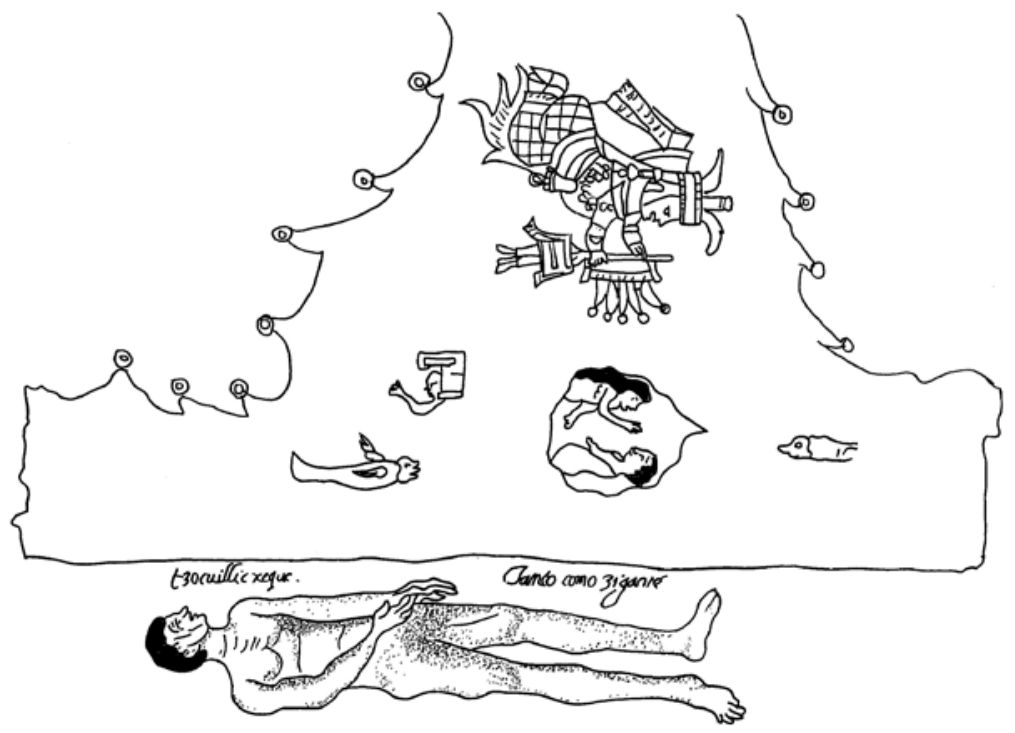

Fuente: Códice Vaticano A, 1996, fol. 4v. Dibujo de Jaime Echeverría.

correspondencia con los Anales de Cuaubtitlan ${ }^{157}$ cuando señalan que los gigantes solían saludarse diciendo "no se vaya a caer usted" (Ma timohuetziti), porque el que se caía ya no se volvía a levantar. La poca estabilidad de los gigantes se explica a partir de la deformidad de sus pies o sus piernas. ${ }^{158}$

${ }^{157}$ Rafael Tena Martínez, ed., Anales de Cuauhtitlan (México: Consejo Nacional para la Cultura y las Artes, Cien de México, 2011), 30-31.

${ }^{158}$ Ferdinan Anders y Maarten Jansen, Religión, costumbres e historia de los antiguos mexicanos. Libro explicativo del llamado Códice Vaticano A (México: Akademische DruckUnd Verlagsanstalt, Fondo de Cultura Económica, 1996), 56, sugieren una lectura diferente del término tzocuillicxeque; para ellos posiblemente significa "los que tienen tres pies". Para sugerir esto, se basan en Sahagún, y cito a los autores: "La terminación icxeque sin duda se traduce como "los que tienen pies", pero la primera parte de la palabra es de interpretación más problemática. Molina registra en su diccionario tzocuil, "jilguerito", 
Quiero traer a colación una reveladora afirmación de Olivier ${ }^{159}$ citada páginas atrás: "personajes con los miembros inferiores mutilados [...] anuncian el fin de las eras o de los reinos". A la luz de esta aseveración, Alvarado Tezozómoc pudo haber insertado deliberadamente la figura del gigante en su relato de los presagios de la conquista de Tenochtitlan. Y podría también no ser casualidad que lo nombrara con el término tezocuilycxique -el cual alude justamente a la malformación de sus pies-y no con otro de sus nombres: tlacahueyac (literalmente, "persona larga"), como lo hace la Leyenda de los Soles ${ }^{160}$ que igualmente es un texto de tradición tenochca. Asimismo, resulta significativo que Tezozómoc aludiera varias veces a seres con ausencia de una de las extremidades inferiores o con características particulares en éstas: tenemos a los centeycxique, gente que posee solamente un pie pero de grandes proporciones; los coayxeequee (sic,

pero Sahagún [...] utiliza la expresión, muy semejante, tzicujlicxe como sinónimo de ey $i c x i$, "tres pies". La información que retoman los autores del franciscano corresponde a la descripción de la fiesta de Tlacaxipehualiztli del Códice Florentino. En una parte se dice que, y sigo la traducción de Anderson y Dibble, $C F$, lib. II, cap. XXII, 59: "el dueño del cautivo colocaba, ponía en el patio [de su casa] una bola de ramas tejida sobre tres pies; tenía pies pequeños" ("the owner of the captive set up, put in place in the courtyard [of his house] a woven twig ball on three feet; it had little feet") (quiquetza in male, qujtlalia quauhtzontapaiolli, ey icxi, tzicujlicxe). Y por su parte, fray Bernardino de Sahagún, Historia general, tomo I, lib. II, cap. XxII, 187, dio la versión del mismo pasaje en los siguientes términos: "el dueño del esclavo que había muerto ponía en el patio de su casa un globo redondo, hecho de petate, con tres pies, y encima del globo ponía todos los papeles con que se había aderezado el captivo cuando murió”. Ni en el texto en náhuatl ni en ninguna de las dos traducciones anteriores se toman como sinónimos ey icxi, "tres pies" y tzicujlicxe, que literalmente significa "el que tiene pies flacos" (véase la entrada del Vocabulario de Molina, 2004, sección náhuatl-español: f. 152r, tzicuiliui, que traduce como "pararse muy flaco, o tollirse"). En otra parte del libro in del Florentino vuelven a aparecer juntos los dos conceptos anteriores, cuando se habla de un tipo de vasijas que se utilizaban para beber llamadas tzicujltecomatl, las cuales tenían tres pies (ei icxi), CF, lib. II, cap. XxxVIII, 171. En los dos pasajes los pies deben de entenderse como soportes. Entonces, tanto la bola de petate como el "tecomate flaco" se caracterizaban por tener tres soportes delgados, y de ninguna manera pueden considerarse como sinónimos los términos ey icxi y tzicujlicxe. Lo que sí es que el vocablo tzicuili seguramente está relacionado con tzocuili, y aludiría a las delgadas patas del jilguero. Asimismo, resulta interesante que el mismo concepto tzicuili refiera al tullido, pues, aportaría un dato más sobre la discapacidad que padecían los gigantes.

${ }^{159}$ Guilhem Olivier, "Homosexualidad y prostitución”, 415, nota 8.

${ }^{160}$ Leyenda de los Soles, 192-194. 
coaicxique), de "piés de gusanos, gentes de un pie"; y señala nuevamente que "vendrán luego otros de un pie". No obstante que el historiador tenochca nutrió su Crónica mexicana del repertorio teratológico de Occidente, ${ }^{161}$ supo escoger seres monstruosos con seńas particulares que resultaban afines a la cosmovisión nahua, y que se insertaban bastante bien en los eventos de fin de un imperio. El carácter predictivo del gigante se refuerza con su aparición previa a la caída de Tollan, en donde debió cumplir el mismo rol que en el contexto mexica: anunciar la destrucción de un imperio y la instauración de uno nuevo. Como recomendación metodológica, antes de descartar determinada información de las crónicas novohispanas por considerarse una "influencia occidental", se debería de reflexionar sobre su inclusión a partir de la cosmovisión mesoamericana. Y esto es justamente lo que se acaba de hacer con respecto a los gigantes de Tezozómoc.

De acuerdo con Muñoz Camargo: ${ }^{162}$

Todas estas señales y otras [...] a los naturales les pronosticaban su fin y acabamiento, porque decían que había de venir la fin y que todo el mundo se había de acabar y consumir, e que habían de ser creadas otras nuevas gentes y venir otros nuevos habitadores del mundo, y ansí andaban tan tristes y despavoridos, que no sabían qué juicios sobre esto hubiesen de echar....

${ }^{161}$ A propósito de los seres con la cabeza en el pecho de que habló Alvarado Tezozómoc, y que se identifican con los blemis de Occidente como se dijo arriba, los indios kaliña de Surinam han conformado un amplio repertorio de razas monstruosas en el que incluyen a los paira-undepo, gente caníbal que, según la mitología kaliña, fue traída por los europeos para aniquilar a los indígenas. Ellos tenían una boca en el estómago, otra en la rodilla izquierda y una más en el codo derecho, Edmundo Magaña, "Hombres Salvajes y Razas Monstruosas de los indios Kaliña de Surinam”, Journal of Latin American Lore 8(1) (verano 1982): 75, 87. A pesar de que Magańa reconoce que este tipo de ser monstruoso -y otros más- se encuentra en los autores clásicos, y de que los viajeros europeos proyectaron sus razas monstruosas en el territorio americano, también afirma que "al menos una parte de los relatos de los viajeros sobre pueblos monstruosos [de los kaliña] provenía efectivamente de informantes nativos”, Ibid, 65. Esto lo lleva a la siguiente reflexión: "si en todas partes la imaginación etnológica muestra ser similar, es que ésta es el producto de procesos mentales y/o culturales también similares”, Ibid., 67. La subestimación de los paralelismos en las creaciones culturales de Europa y América nos puede llevar a una mala comprensión de determinados aspectos de la cosmovisión indígena americana.

${ }_{162}$ Diego Muńoz Camargo, Historia de Tlaxcala, 177-178. 
Siguiendo con el modelo de fin de una era y de caída de imperios, la transgresión del gobernante era el detonante. Así como ocurrió con Quetzalcóatl en Tollan y con Maxtla durante la hegemonía tepaneca, la explicación que se dio después de la Conquista sobre el ocaso del Sol mexica consistió en las faltas de Motecuhzoma Xocoyotzin. De ahí que se le acusara de soberbia, de desprecio hacia todos, de estar fuera de sí, y, sobre todo, de haber querido hacerse más grande que el dios mismo. ${ }^{163} \mathrm{Y}$, como ha señalado Guilhem Olivier ${ }^{164}$ restaría la imputación de transgresiones sexuales al tlatoa$n i$ tenochca. El estudioso recuerda las acusaciones de homosexualidad lanzadas contra Motecuhzoma, al tratar de apaciguar a los mexicas después de la matanza del Templo Mayor efectuada por los españoles. ${ }^{165}$

\section{Conclusiones}

A lo largo del texto he sostenido la idea de que toda caída de un imperio en el mundo náhuatl era concebida como un cambio de era, el cual siguió un modelo mítico-histórico en la reconstrucción $a$ posteriori de los acontecimientos. Este modelo correspondió con la concepción cíclica indígena de la historia, donde los eventos del pasado eran interpretados a partir del presente, y éste cobraba sentido a la luz de los acontecimientos acaecidos. Esta manera de concebir el tiempo igualmente permitía anticipar el futuro. Con base en la dialéctica de los opuestos, el imperio que estaba a punto de sucumbir mostraba los signos de su degradación, que eran personificados en la figura del tlatoani; mientras que el nuevo orden representaba los valores contrarios positivos. Entonces, todo gobernante de un imperio que llegaba a su ocaso o de una ciudad en decadencia mostraba un comportamiento transgresor. Es en este tiempo

${ }^{163}$ Fray Diego Durán, Historia de las Indias, tomo I, tratado I, cap. LXvI, 556, cap. LXVII, 561; Michel Graulich, Moctezuma. Apogeo y caída del imperio azteca, trad. Tessa Brisac (México: Ediciones Era/INAH 2014), 456.

${ }^{164}$ Guilhem Olivier, "Homosexualidad y prostitución", 322.

${ }^{165}$ Ibid., 322-323; véase fray Bernardino de Sahagún, Historia general, tomo III, lib. XII, cap. XXI, 1,195. 
que el soberano encarnaba el sol del atardecer, un sol menguado que, por ende, exhibía características asociadas con su astro opuesto: la luna. El gobernante decadente, entonces, se identificaba con los excesos sexuales, la debilidad, la oscuridad y lo frío, tal como ocurrió con Quetzalcóatl, Huémac, ${ }^{166}$ Maxtla, ${ }^{167}$ Motecuhzoma Xocoyotzin -quien se identificó en sus acciones previas a la Conquista con Huémac- ${ }^{168}$ y sin lugar a dudas puede incluirse en esta lista a Moquihuix, ${ }^{169}$ tlatoani de Tlatelolco en tiempos de Axayácatl.

Los últimos días de un imperio se caracterizaron por la presencia de señales celestes y terrestres ominosas que, pensadas desde el presente, fueron interpretadas como vaticinios de destrucción. Los augurios o tetzahuitl recurrentes en la reconstrucción de los eventos fueron el eclipse de sol y el cometa. De forma individual, su presencia auguraba eventos desastrosos para la clase gobernante: la muerte del tlatoani y de nobles importantes. En su conjunción, los tetzahuitl agoraron un acontecimiento de mayores repercusiones: el fin de una era. Pero para que la narración de los acontecimientos se ajustara al modelo, debía de presenciarse otro tetzahuitl, la figura monstruosa.

En términos metodológicos, debí haber expuesto desde un inicio lo que entiendo por monstruo, pero decidí reservarlo para el final con el objetivo de ofrecer una visión de lo monstruoso a partir de las evidencias ya expuestas. En la concepción nahua, el monstruo era todo aquel ser que rebasaba los límites de lo natural, y generalmente se tomó como punto de referencia la constitución humana; así, su característica más común fueron las exageradas medidas corporales, como en el caso del gigante. Pero también podemos mencionar otros rasgos como la abundante pilosidad y su consistencia encres-

${ }^{166}$ Michel Graulich, Mitos y rituales, 211-212; Guilhem Olivier, "Homosexualidad y prostitución", 278-279.

${ }^{167}$ Clementina Battcock, “Aspectos simbólicos”, 224-225.

${ }^{168}$ Patrick Johansson, "La muerte de Moctezuma: la historia y el mito desde una perspectiva levistraussiana”, en Lévi-Strauss: un siglo de reflexión, coord. María Eugenia Olavarría, Saúl Millán y Carlo Bonfiglioli (México: Juan Pablos, Universidad Autónoma Metropolitana-Iztapalapa, 2010); Rocío Cortés, "Motecuzoma/Huemac"; Michel Graulich, Moctezuma, 456.

${ }^{169}$ Michel Graulich, Mitos y rituales, 266-267. 
pada; la ausencia de alguna extremidad inferior, su malformación o su sustitución por un objeto, tal como ocurrió con el lobo con patas de palo que se apareció en tiempos de la hegemonía tepaneca. ${ }^{170}$ Estos rasgos en las extremidades nos llevan a una segunda característica fundamental del monstruo prehispánico: su naturaleza transgresora. Cecelia Klein ${ }^{171}$ ha afirmado que los cuerpos, extremidades y cabezas volteados o contorsionados, especificaron con frecuencia en los códices la conducta sexual desordenada. Mientras que Guilhem Olivier ha visto en la ausencia del pie de Tezcatlipoca una metáfora de la mancha sexual. ${ }^{172}$ En la figura del gigante se concentran, además de su talla exagerada, una malformación en los pies, una apariencia desalineada y una práctica sexual reprobada: se decía que tenían el cabello largo y desmarañado y que eran homosexuales. ${ }^{173}$ Entonces, la deformidad física del monstruo aludía a su inmoralidad. Aunque solamente contamos con el ejemplo de los gigantes para afirmarlo, considero que se puede extender esta idea a toda figura monstruosa prehispánica.

La apariencia física desproporcionada, deformada o incompleta del monstruo, así como la indicación en él de un comportamiento moral transgresor a partir de dicha apariencia, se oponían al ideal del ser humano tanto en su constitución física externa como en su comportamiento. Al ser proyectado este juego de oposiciones a un imperio que sucumbía, el monstruo se asimilaba a la degradación moral de su gobernante y su población; de esta manera, vaticinaba el estado de desorden que reinaba en determinado imperio a la vez que anunciaba la llegada de otro de una calidad moral incuestionable.

${ }^{170}$ Estas características pueden indicar rasgos monstruosos en ciertas personas o divinidades, sin que ello implique una naturaleza monstruosa por sí misma. Tal es el caso de la cabellera crespa de Quetzalcóatl, según la versión de Alva Ixtlilxóchitl comentada páginas atrás. Este tipo de cabellera aludió a concepciones negativas que presagiaron la caída de Tollan, pero no por ello Quetzalcóatl se consideró un ser monstruoso.

${ }^{171}$ Cecelia Klein, "None of the Above: Gender Ambiguity in Nahua Ideology", en Gender in Prehispanic America, ed. Cecelia F. Klein (Washington: Dumbarton Oaks, 2001), 208.

${ }^{172}$ Guilhem Olivier, Tezcatlipoca, 423.

${ }^{173}$ Durán, Historia de las Indias, tomo I, tratado primero, cap. II, 66; Veytia, op. cit., tomo I, lib. I, cap. III, 20; cap. XII, 105; cap. XIII, 108. 
Agradecimientos

Agradezco los comentarios y las críticas de los dictaminadores que indudablemente ayudaron a mejorar la versión inicial de este trabajo.

\section{BIBLIOGRAFÍA}

Alcalá, Jerónimo de. Relación de Michoacán, estudio introductorio Jean-Marie G. Le Clézio. Zamora: El Colegio de Michoacán, 2008. Alva Ixtlilxóchitu, Fernando de. Sumaria relación de todas las cosas que han sucedido en la Nueva España, y de muchas cosas que los tultecas alcanzaron y supieron desde la creación del mundo, hasta su destrucción y venida de los terceros pobladores chichimecas, hasta la venida de los españoles, sacada de la original historia de esta Nueva España. En Obras Históricas, tomo I, ed. Edmundo O'Gorman, 261-393. Toluca: Instituto Mexiquense de Cultura, Universidad Nacional Autónoma de México, Instituto de Investigaciones Históricas, 1997a.

. Compendio histórico del reino de Texcoco. En Obras Históricas.

Tomo I, ed. Edmundo O'Gorman, 415-521. Toluca: Instituto Mexiquense de Cultura, Universidad Nacional Autónoma de México, Instituto de Investigaciones Históricas, $1997 \mathrm{~b}$.

. Historia de la nación chichimeca. En Obras Históricas. Tomo II, ed. Edmundo O'Gorman, 5-263. Toluca: Instituto Mexiquense de Cultura, Universidad Nacional Autónoma de México, Instituto de Investigaciones Históricas, 1997c.

Alvarado Tezozómoc, Hernando. Crónica Mexicana, notas de Manuel Orozco y Berra. México: Editorial Leyenda, 1944.

Crónica mexicana, precedida del Códice Ramirez manuscrito del siglo Xvi intitulado: Relación del origen de los Indios que habitan esta Nueva España según sus historias. Biblioteca Porrúa de Historia 61, ed. Manuel Orozco y Berra. México: Editorial Porrúa, 1987. Anales de Cuaubtitlan, en Códice Chimalpopoca. Anales de Cuauhtitlan y Leyenda de los Soles, trad. Primo Feliciano Velázquez, 3-68. México: Universidad Nacional Autónoma de México, Instituto de Historia, Imprenta Universitaria, 1945. 
Anales de Cuauhtitlan, ed. Rafael Tena Martínez. México: Consejo Nacional para la Cultura y las Artes, Cien de México, 2011. ANDERs, Ferdinan y Maarten JANSEN, Religión, costumbres e historia de los antiguos mexicanos. Libro explicativo del llamado Códice Vaticano A. México: Akademische Druck-Und Verlagsanstalt, Fondo de Cultura Económica, 1996.

Batтсоск, Clementina. "Aspectos simbólicos, representaciones y significaciones de las diferentes muertes de Maxtla: una propuesta de análisis". Estudios de Cultura Nábuatl (40) (2009): 215-234.

BAudot, Georges. "Alteridad y monstruosidad: el enfrentamiento de los modelos culturales". Cuadernos Americanos. Nueva-época, año vi 6(36) (noviembre-diciembre, 1992): 46-55.

. "Nezahualcóyotl, príncipe providencial en los escritos de Fernando de Alva Ixtlilxóchitl”. Estudios de Cultura Nábuatl (25) (1995): 17-28.

Benavente, fray Toribio de (Motolinía). Memoriales (Libro de oro, MS JGI 31). Biblioteca Novohispana 3, ed. Nancy Joe Dyer. México: El Colegio de México, Centro de Estudios Lingüísticos y Literarios, 1996.

BoiA, Lucian. Entre el ángel y la bestia, trad. Andrea Morales Vidal, Barcelona: Editorial Andrés Bello, 1997.

Códice Aubin, versión de 1902 publicada por Antonio Peñafiel. México: Editorial Innovación, 1980.

Códice Telleriano-Remensis. En Antigüedades de México, basadas en la recopilación de Lord Kingsborough, vol. I, ed. José Corona Núñez, 151-337. México: Secretaría de Hacienda y Crédito Público, 1964.

Códice Vaticano A, ed. Ferdinan Anders y Maarten Jansen. Austria: Akadmische Druck-und Verlagsanstalt, Fondo de Cultura Económica, 1996.

Códice Vaticano Latino 3738. En Antigüedades de México, basadas en la recopilación de Lord Kingsborough, vol. III, ed. José Corona Núnez, 1-314. México: Secretaría de Hacienda y Crédito Público, 1964.

CorTÉs, Rocío. “Motecuzoma/Huemac y Quetzalcoatl/Cortés: re- 
ferencia mítica sobre el fin del imperio mexica en la Crónica mexicana de don Hernando de Alvarado Tezozomoc". Hofstra Hispanic Review (3) (otoño 2006): 26-40.

"Costumbres, fiestas enterramientos y diversas formas de proceder de los indios de Nueva España”, publicado por Federico Gómez de Orozco, Tlalocan 2(1) (1945): 37-63.

Chimalpain Cuauhtrehuanitzin, Domingo Francisco de San Antón Munón, Memorial breve acerca de la fundación de la ciudad de Culhuacan, Serie de Cultura Náhuatl, Fuentes 9, ed. Víctor M. Castillo F. México: Universidad Nacional Autónoma de México, Instituto de Investigaciones Históricas, 1991.

Dibble, Charles E. Códice Xolotl. Primera Serie, núm. 22. México: Universidad Nacional Autónoma de México, University of Utah, 1951.

Durán, fray Diego. Historia de las Indias de Nueva España e islas de tierra firme, 2 tomos, ed. Rosa Camelo y José Rubén Romero. México: Consejo Nacional para la Cultura y las Artes, Cien de México, 2002.

ECheverría García, Jaime. “'El Sol es comido’: representaciones, prácticas y simbolismos del eclipse solar entre los antiguos nahuas y otros grupos mesoamericanos". Revista Española de Antropología Americana 44(2) (2014): 367-391.

. "Entre la fertilidad agrícola y la generación humana: el rol fecundante del mono entre los antiguos nahuas". Estudios de Cultura Nábuatl (50) (julio-diciembre 2015): 207-259.

Echeverría García, Jaime y Miriam López Hernández. “La expresión corporal del miedo entre los antiguos nahuas". Anales de Antropología 47(1) (junio 2013): 143-166.

Graulich, Michel. Mitos y rituales del México antiguo, trad., Ángel Barral Gómez. Madrid: Colegio Universitario de Ediciones Istmo, 1990.

"Los presagios de la caída del imperio azteca", Cuicuilco (31/32) (julio/diciembre, 1992): 93-100.

Moctezuma. Apogeo y caida del imperio azteca, trad. Tessa Brisac. México: Ediciones Era/InAH, 2014.

Guiteras Holmes, Calixta. Los peligros del alma. Visión del mundo 
de un tzotzil, trad. Carlo Antonio Castro. México: Fondo de Cultura Económica, 1996.

"Histoyre du Mechique". En Mitos e historias de los antiguos nahuas, trad. Rafael Tena Martínez. México: Consejo Nacional para la Cultura y las Artes, Cien de México, 2002, 123-165.

Johansson, Patrick. "La muerte de Moctezuma: la historia y el mito desde una perspectiva levistraussiana”, coord. María Eugenia Olavarría, Saúl Millán y Carlo Bonfiglioli. Lévi-Strauss: un siglo de reflexión, 197-226. México: Juan Pablos, Universidad Autónoma Metropolitana-Iztapalapa, 2010.

. "Presagios del fin de un mundo en textos proféticos nahuas". Estudios de Cultura Nábuatl (45) (enero-junio 2013): 69-147.

KLeIN, Cecelia. "None of the above: gender ambiguity in Nahua ideology”, ed. Cecelia F. Klein, 183-253. Gender in Prehispanic America. Washington: Dumbarton Oaks, 2001.

Las Casas, Bartolomé, fray. Apologética historia sumaria. Cuanto a las cualidades disposición, descripción cielo y suelo destas tierras, y condiciones naturales policias, repúblicas, manera de vivir e costumbres de las gentes destas indias occidentales y meridionales cuyo imperio soberano pertenece a los reyes de Castilla. 2 Tomos, ed. Edmundo O'Gorman. México: Universidad Nacional Autónoma de México, Instituto de Investigaciones Históricas, 1967.

LeÓn-Portilla, Miguel. "Profecías y portentos en vísperas de la conquista”, comp. Leopoldo Zea. Ideas y presagios del descubrimiento de América, 53-82. México: Instituto Panamericano de Geografía e Historia, Fondo de Cultura Económica, 1991.

. "Las profecías del encuentro. Una apropiación mesoamericana del otro". En De palabra y obra en el Nuevo Mundo. 2. Encuentros interétnicos, ed. Manuel Gutiérrez Estévez, Miguel León-Portilla, Gary H. Gossen y J. Jorge Klor de Alva, 225-248. México: Siglo XXI editores, 1992.

LESBRE, Patrick. "Nezahualcóyotl, entre historia, leyenda y divinización". En El héroe, entre el mito y la historia, coord. Federico Navarrete y Guilhem Olivier, 21-55. México: Universidad Nacional Autónoma de México, Centro de Estudios Mexicanos y Centroamericanos, 2000. 
. "El Tetzcutzinco en la obra de Fernando de Alva Ixtlilxóchitl. Realeza, religión prehispánica y cronistas coloniales". Estudios de Cultura Nábuatl (32) (2001): 323-340.

Leyenda de los Soles, en Mitos e historias de los antiguos nahuas, trad. Rafael Tena Martínez. México: Consejo Nacional para la Cultura y las Artes, Cien de México, 2002, 173-205.

López Austin, Alfredo. Cuerpo humano e ideología. Las concepciones de los antiguos nahuas. 2 Tomos. México: Universidad Nacional Autónoma de México, Instituto de Investigaciones Antropológicas, 1996.

"Los animales como personajes del mito". Arqueología Mexicana VI(35) (enero-febrero 1999): 48-55.

López Luján, Leonardo. Tlaltecuhtli. México: Fundación Conmemoraciones 2010, Sextil Editores, Instituto Nacional de Antropología e Historia, 2010.

Magaña, Edmundo. "Hombres Salvajes y Razas Monstruosas de los indios Kaliña de Surinam". Journal of Latin American Lore 8(1) (verano 1982): 63-114.

Mendieta, fray Gerónimo de. Historia eclesiástica indiana. 2 Tomos, ed. Antonio Rubial García. México: Consejo Nacional para la Cultura y las Artes, Cien de México, 2002.

Molina, fray Alonso. Vocabulario en lengua castellana y mexicana y mexicana y castellana, ed. Miguel León-Portilla. México: Editorial Porrúa, 2004.

Muñoz Camargo, Diego. Historia de Tlaxcala (Ms. 210 de la Biblioteca Nacional de París), ed. Luis Reyes García, colaboración de Javier Lira Toledo. México: Gobierno del Estado de México, Ciesas, Universidad Autónoma de Tlaxcala, 1998.

Olivier, Guilhem. "Les paquets sacrés ou la mémoire cachée des Indiens du Mexique central (XVe-XVIe siècles)". Journal de la Société des Américanistes 81(1) (1995): 105-141.

Tezcatlipoca. Burlas y metamorfosis de un dios azteca, trad. Tatiana Sule. México: Fondo de Cultura Económica, 2004. "Homosexualidad y prostitución entre los nahuas y otros pueblos del Posclásico". En Historia de la vida cotidiana en México, I Mesoamérica y los ámbitos indígenas de la Nueva España, dir. 
Pilar Gonzalbo Aizpuru, coord. Pablo Escalante Gonzalbo, 301338. México: Fondo de Cultura Económica, El Colegio de México, 2004.

"Indios y españoles frente a prácticas adivinatorias y presagios durante la conquista de México". Estudios de Cultura Náhuatl (37) (2006): 169-192.

. "Las tres muertes simbólicas del nuevo rey mexica: reflexiones en torno a los ritos de entronización en el México Central prehispánico". En Simbolos de poder en Mesoamérica, coord. Guilhem Olivier, 263-291. México: Universidad Nacional Autónoma de México, Instituto de Investigaciones Antropológicas, Instituto de Investigaciones Históricas, México, 2008.

Olmos, fray Andrés de. Arte de la lengua mexicana. Facsímiles de Lingüística y Filología Nahuas 9, ed. Ascensión Hernández de León-Portilla y Miguel León-Portilla. México: Universidad Nacional Autónoma de México, Instituto de Investigaciones Históricas, 2002.

OudijK, Michel R. "La toma de posesión: un tema mesoamericano para la legitimación del poder", Relaciones Estudios de Historia y Sociedad XXIII(91) (verano 2002): 95-131.

Pastrana Flores, Miguel G. "Los presagios de la conquista como forma de conciencia histórica”. En Estudios Michoacanos VIII, coord. Bárbara Skinfill Nogal y Alberto Carrillo Cázares, 127-142. Zamora: El Colegio de Michoacán, Instituto Michoacano de Cultura, 1999.

- Historias de la Conquista. Aspectos de la historiografia de tradición náhuatl. Serie Teoría e historia de la historiografía 2. México: Universidad Nacional Autónoma de México, Instituto de Investigaciones Históricas, 2009.

. "La idea de tetzahuitl en la historiografía novohispana". Estudios de Cultura Náhuatl (47) (enero-junio 2014): 237-252.

Ramos de Cárdenas, Francisco. "Relación de Querétaro". En Relaciones geográficas del siglo XV: Michoacán. Vol. 9, ed. René Acuña, 206-248. México: Universidad Nacional Autónoma de México, Instituto de Investigaciones Antropológicas, 1987.

Sahagún, Bernardino de, fray. Florentine Codex, ed. Charles E. 
Dibble y Arthur J. O. Anderson. Santa Fe: The School of American Research, The University of Utah, 1950-1983.

. Augurios y abusiones. Serie Cultura Náhuatl, Fuentes 7, ed. Alfredo López Austin. México: Universidad Nacional Autónoma de México, Instituto de Investigaciones Históricas, 1969.

. Códice Florentino. Edición facsimilar. 3 Tomos. México: Archivo General de la Nación, 1979.

. Los once discursos sobre la realeza. Libro sexto del Códice Florentino, ed. Salvador Díaz Cíntora. México: Universidad Nacional Autónoma de México, 1995.

. Primeros Memoriales, ed. Thelma Sullivan, completado, revisado y con adiciones por H. B. Nicholson. Norman: University of Oklahoma, 1997.

. Historia general de las cosas de la Nueva España. 3 Tomos, ed. Alfredo López Austin y Josefina García Quintana. México: Consejo Nacional para la Cultura y las Artes, Cien de México, 2002. Santamarina Novillo, Carlos. "El sistema de dominación azteca: el imperio tepaneca". Tesis de Doctorado, Universidad Complutense de Madrid, 2005.

Siméon, Rémi. Diccionario de la lengua náhuatl o mexicana, trad. Josefina Oliva de Coll. México: Siglo XXI, 2002.

TORQUEMADA, Juan de, fray. Monarquía Indiana de los veinte y un libros rituales y monarquía indiana, con el origen y guerras de los indios occidentales, de sus poblazones, descubrimiento, conquista, conversión y otras cosas maravillosas de la mesma tierra. Serie de historiadores y cronistas de Indias 5. 7 Vols., edición preparada por el Seminario para el estudio de fuentes de tradición indígena, bajo la coordinación de Miguel León-Portilla. México: Universidad Nacional Autónoma de México, Instituto de Investigaciones Históricas, 1975.

UMBerger, Emily Good. "Antiques, Revivals, and References to the Past in Aztec Art". RES, Anthropology \& Aesthetics (13) (primavera 1987): 63-105.

Veytia, Mariano. Historia antigua de México. 2 Tomos. México: 